INRA Prod. Anim., 2010, 23 (3), 285-304

\title{
Etude des cinétiques de dégradation dans le rumen des constituants pariétaux des aliments concentrés et coproduits agroindustriels
}

\author{
P. CHAPOUTOT, M. DORLEANS', D. SAUVANT
}

INRA, UMR791 Modélisation Systémique Appliquée aux Ruminants, 16 rue Claude Bernard, F-75231 Paris, France AgroParisTech, Département Sciences de la Vie, 16 rue Claude Bernard, F-75231 Paris, France

Courriel : patrick.chapoutot@agroparistech.fr

La mesure de la dégradation dans le rumen du NDF est un bon prédicteur de la fraction pariétale indigestible des aliments qui est le déterminant principal de leur valeur énergétique chez les ruminants. Cette étude analyse la grande variabilité des paramètres de dégradation des constituants pariétaux observée sur plus de 200 échantillons d'environ 80 aliments concentrés et coproduits. La base de données ainsi créée permettra de compléter les tables d'alimentation des ruminants et de nourrir les travaux de modélisation de la digestion dans le rumen.

$\mathrm{Au}$ cours des trois dernières décennies, la méthode in situ a été largement utilisée pour mesurer la dégradation des constituants dans le rumen. Elle a été une étape essentielle pour quantifier la protéolyse ruminale dans les systèmes des protéines digestibles chez les ruminants (Madsen 1985, Vérité et al 1987, Nozières et al 2007). Cette méthode in situ a également été proposée pour apprécier la partition de la dégradation de l'amidon et la prévision de son absorption dans le tube digestif (Tamminga et al 1990, Nocek et Tamminga 1991, Sauvant et al 1994, Offner et al 2003, Offner et Sauvant 2004, Sauvant et al 2004) ou pour évaluer le pouvoir d'encombrement des aliments (Madsen et al 1994, Stensig et al 1994, Baumont et al 1996) et leur pouvoir acidogène dans le rumen (De Smet et al 1995, Apper-Bossard et al 2006, Peyraud et Apper-Bossard 2006).

En alimentation des ruminants, aucune méthode de laboratoire n'a encore été proposée pour quantifier la fraction indigestible des parois végétales, qui représente le déterminant principal de la teneur en énergie nette des aliments et des régimes (Jarrige 1981). Néanmoins, les résultats obtenus par Archimède et al (1995a et b) et d'autres analyses des données de la littérature (Sauvant et al 2007) témoignent que la méthode in situ permet une bonne évaluation de la fraction pariétale indigestible des régimes. Par ailleurs, Sauvant et al (2008) ont montré que la dégrada- bilité in situ de la fraction NDF des aliments concentrés et coproduits était étroitement reliée à la digestibilité du NDF estimée à partir des fractions azotée, amylacée et lipidique indigestibles.

Jusqu'à présent, plusieurs études ont été publiées sur la dégradation dans le rumen des parois des fourrages, mais peu d'auteurs ont étudié de façon systématique la dégradation des constituants pariétaux des aliments concentrés, et les travaux publiés actuellement concernent un nombre limité de matières premières : Varga et Hoover (1983; 22 aliments), Sauvant et al (1986a et b; 24), Tamminga et al (1990; 32), Aronen et al (1991; 3), Khorasani et al (1994; 4), Torrent et al (1994; 4), Hindle et al (1995; 7), DePeters et al (1997 ; 9), Fadel et al (2000; 8). De plus, aucune revue quantitative n'a été publiée sur ce sujet. La synthèse présentée par Nocek et Russel (1988) sur des aliments concentrés portait sur des mesures in situ mais également sur des données in vitro et in vivo. De plus, nombre de données proposées par Tamminga et al (1990) ont été estimées à partir de la bibliographie et aucunes références ne sont associées aux données utilisées dans le système de Cornell (Sniffen et al 1992).

Les constituants pariétaux peuvent présenter des dynamiques de dégradation très variées selon les aliments avec, pour certains, un temps de latence particulièrement marqué (figure 1).
De nombreux modèles ont déjà été proposés dans la littérature pour ajuster au mieux les cinétiques de dégradation dans le rumen, avec ou sans phase de latence, avec un ou plusieurs compartiments, et leurs capacités d'ajustement ont été discutées (Lopez et al 1999, Ellis et al 2005, Huhtanen et al 2008).

L'objectif de cette étude était d'apporter les bases d'un système d'évaluation des paramètres de la dégradation in situ des constituants pariétaux, et de décrire les principaux déterminants des fractions indigestibles des aliments concentrés et coproduits. Pour cela, un grand nombre d'échantillons d'aliments divers ont été testés à travers une méthodologie standardisée d'incubation dans le rumen et en appliquant de façon systématique deux modèles d'ajustement afin de proposer des paramètres de la dégradation des parois végétales des aliments concentrés et coproduits à partir d'un jeu de données homogènes: le modèle monomoléculaire d'Ørskov et McDonald (1979) classiquement utilisé dans la bibliographie et le modèle de Mertens (1973) qui tient compte d'un temps de latence progressif. Seuls Sauvant et al (1986a et b) ont utilisé ce dernier modèle dans leurs études pour 9 des 24 matières premières étudiées qui présentaient une phase de latence au démarrage de la cinétique de dégradation des parois. Il méritait donc d'être validé sur un nombre plus important de données. 
Figure 1. Evolution de la quantité résiduelle de NDF de quelques aliments après incubation dans le rumen (Chapoutot 1998).

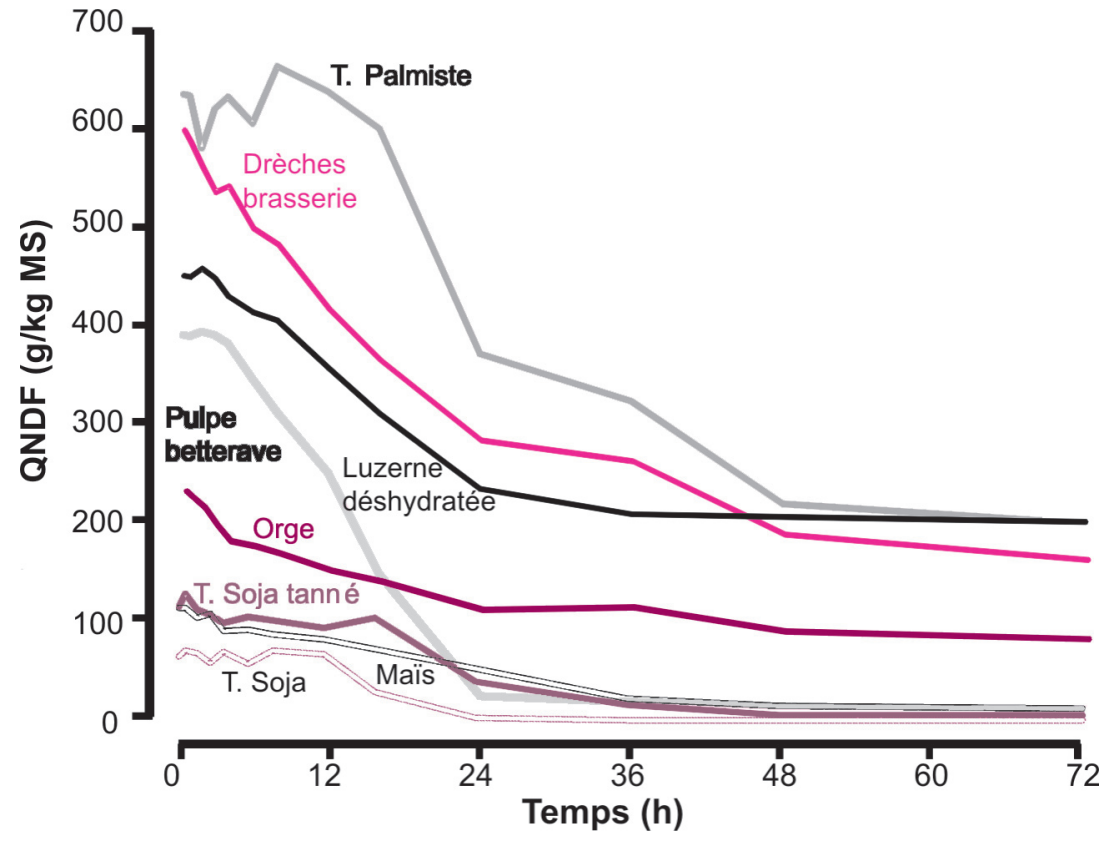

\section{1 / Constitution de la base de données}

Les mesures in situ ont été réalisées sur un ensemble de 217 échantillons d'aliments représentant 78 matières premières (200 échantillons) et 17 mélanges simples ou aliments composés.

\section{1 / Méthodologie de mesure de la dégradation in situ}

Les incubations dans le rumen ont été conduites au cours de 19 essais expérimentaux en utilisant la méthode des sachets de Nylon. Les principales caractéristiques de cette méthode ont été décrites par Michalet-Doreau et al (1987). Dans nos essais, les animaux munis de canules du rumen étaient des chèvres et des vaches taries (respectivement 8 et 11 essais). Les régimes étaient constitués (sur la base de la matière sèche, MS) de $70 \%$ de foin de luzerne pour les chèvres ou de graminées pour les vaches et de $30 \%$ d'aliments concentrés du commerce (de 15 à $18 \%$ de MAT sur brut) et distribués au niveau de l'entretien en 2 repas égaux $(9 \mathrm{~h}$ et $17 \mathrm{~h})$.

Les échantillons d'aliments ont été utilisés tels quels pour les aliments secs et séchés à l'étuve ou par lyophilisation pour les aliments frais, puis broyés sur une grille de 0,8 ou $1 \mathrm{~mm}$. Environ $3 \mathrm{~g}$ d'échantillon ont été introduits dans les sachets de nylon (vide de maille entre 46 et $60 \mu$ ), conduisant à un rapport masse d'échantillon/surface du sachet d'environ 12 à $20 \mathrm{mg} / \mathrm{cm}^{2}$. Les sachets (6 à 9 répétitions par échantillon et par temps) ont été placés dans le rumen juste avant le repas du matin et retirés après différentes durées d'incubation jusqu'à 48 ou parfois $72 \mathrm{~h}$ pour certaines matières premières à dégradation lente (les durées les plus fréquentes étant : 1 ou 2 h, 3 ou 4 h, 6 ou 8 h, 12 ou $16 \mathrm{~h}, 24 \mathrm{~h}, 48 \mathrm{~h}$, parfois 36 et $72 \mathrm{~h}$ ). selon les essais, mais tous étaient basés sur des plans factoriels ou en carré latin, afin de prendre en compte les principaux effets (aliment, animal et série). De plus, dans tous les essais, un ou plusieurs aliments témoins ont été introduits dans chaque animal et pour chaque série, pour différentes durées d'incubation, de façon à prendre en compte les variations d'activité microbienne entre animaux, périodes et essais : tourteau de soja $(4 \mathrm{~h})$, luzerne déshydratée $(8 \mathrm{~h})$, maiis grain $(16 \mathrm{~h})$, paille d'avoine (24 h). Les données de dégradation de la MS de ces aliments témoins ont été utilisées pour corriger les résultats de dégradation de la MS des aliments riance.

Après incubation, les sachets ont été rincés à l'eau courante, lavés en machine pendant 2 cycles de $10 \mathrm{~min}$ puis congelés pour stopper l'activité microbienne. Les sachets ont ensuite été séchés à l'étuve pendant $24 \mathrm{~h}$ à $80^{\circ} \mathrm{C}$ dans la majorité des essais, ou lyophilisés pour un essai. La proportion de MS disparue des sachets (DMS, en \%) a été calculée pour chaque répétition et chaque temps d'incubation par pesées des sachets vides et de l'échantillon sec Les dispositifs expérimentaux ont varié expérimentaux par analyse de cova- introduit avant incubation puis des sachets séchés après incubation.

\section{2 / Analyses chimiques}

Les échantillons d'aliments ont été analysés pour quantifier leurs teneurs en MS $\left(103^{\circ} \mathrm{C}\right.$ pendant $\left.4 \mathrm{~h}\right)$, cendres (MM, $550{ }^{\circ} \mathrm{C}$ pendant $4 \mathrm{~h}$ ), MAT (N Kjeldahl $\times 6,25)$ et cellulose brute $(\mathrm{CB}$, méthode Weende). Les constituants pariétaux ont été déterminés sur les aliments avec un appareil FIBERTEC SYSTEM 1010 (Perstorp Analytical S.A., Bezons, France) par la procédure de Dorléans (1985), dans laquelle le résidu au détergent neutre (NDF) est mesuré avec la méthode de Van Soest et Wine (1967) sans sulfite de sodium ni décaline, et en appliquant différents prétraitements si nécessaire selon la nature des aliments : 10 min à ébullition dans l'eau, pré-extraction à l'éther éthylique et prétraitement à l' $\alpha$-amylase et/ou protéase. Le résidu au détergent acide (ADF), puis la fraction lignine obtenue à l'acide sulfurique $72 \%$ (ADL), a été dosé de manière séquentielle sur le résidu NDF par la méthode de Goering et Van Soest (1970).

Après incubation, à partir des sachets ne présentant pas des valeurs de DMS anormales (cf. $\S 1.3 a$ ), les résidus pour chaque échantillon et chaque durée d'incubation ont été regroupés, selon les essais, sur l'ensemble des animaux, par animal, par série ou par animal $\times$ série. Les résidus poolés ont été séchés à l'étuve à $80^{\circ} \mathrm{C}$ pendant $24 \mathrm{~h}$, puis les constituants pariétaux (NDF, ADF, ADL) ont été analysés en séquentiel sur une prise d'essai de 0,5 g de MS. Cependant, contrairement aux aliments, le NDF a été dosé sur les résidus d'incubation sans aucun prétraitement, en faisant l'hypothèse que les constituants cellulaires qui pourraient interférer dans le dosage du NDF (amidon et/ou protéines associées aux parois) ont été largement solubilisés ou dégradés pendant la phase d'incubation.

\section{3 / Traitements des données}

\section{a) Analyses statistiques}

Pour chaque essai, les valeurs individuelles de DMS ont été analysées statistiquement afin de détecter les observations aberrantes : après une analyse de variance qui prend en compte les principaux effets du dispositif expérimental, le test d'Anscombe et Tukey (Snedecor et Cochran 1984) a été appliqué pour tester statistiquement si certaines données présentaient des valeurs résiduelles trop élevées. L'écart admissible a varié selon le dispositif expérimental, mais sur l'ensemble des 19 essais moins de 2,5\% des données initiales ont ainsi été éliminées. 
Dans chaque essai, les quantités résiduelles des constituants pariétaux pour chaque durée d'incubation : QNDF $(\mathrm{t})$, QADF $(\mathrm{t}), \quad \mathrm{QADL}(\mathrm{t})$ exprimées en $\%$ MS initiale, ont été calculées pour chacune des 6 à 9 répétitions par échantillon à partir des données individuelles de DMS $(\mathrm{t})$ et des teneurs moyennes de chaque constituant dans les résidus poolés.

Afin de corriger les effets «essais», les quantités moyennes QNDF(t), $\operatorname{QADF}(\mathrm{t}), \mathrm{QADL}(\mathrm{t})$ pour chaque échantillon sur l'ensemble des 19 essais ont été estimées statistiquement à chaque temps d'incubation $(t)$ à partir des moyennes ajustées issues d'une analyse de variance-covariance intégrant les DMS des témoins par la procédure du modèle linéaire généralisé (procédure GLM, SAS 2000) selon le modèle suivant :

$\mathrm{Y}_{\mathrm{ij}}=\mu+\alpha_{\mathrm{i}}+\sum_{\mathrm{k}} \gamma_{\mathrm{k}}\left(\right.$ DMSst $\left._{\mathrm{ijk}}-\overline{\mathrm{DMSst}}_{\mathrm{k}}\right)+\varepsilon_{\mathrm{ij}}$

Avec :

$\mathrm{Y}_{\mathrm{ij}}$ : quantité dégradée pour l'échantillon $i$ et la répétition $j$ au temps $t$

$\alpha_{i}$ : effet échantillon d'aliment

$\overline{\mathrm{DMSst}}_{\mathrm{ijk}}$ : disparition de la MS mesurée pour le témoin $\mathrm{k}$ associé à l'échantillon $i$ lors de la répétition $j$ et utilisée comme covariable pour corriger l'effet essai

DMSst $_{\mathrm{k}}$ : disparition moyenne de la MS mesurée pour le témoin $k$ sur l'ensemble des essais

$\gamma_{\mathrm{k}}$ : coefficient de régression pour la covariable $k$

$$
\varepsilon_{\mathrm{ij}} \text { : erreur résiduelle. }
$$

Le nombre de degrés de liberté pour chaque facteur a varié selon le constituant étudié et la durée d'incubation appliquée.

\section{b) Ajustements des cinétiques de dégradation}

Pour chaque échantillon, les valeurs moyennes QNDF( $\mathrm{t})$ et $\mathrm{QADF}(\mathrm{t})$ obtenues par l'analyse statistique précédente ont été ajustées au cours du temps selon deux modèles d'ajustement non linéaire au moyen de la procédure NLIN de SAS (SAS 2000) :

- Le modèle monomoléculaire adapté par Ørskov et McDonald (1979) pour les cinétiques in situ (modèle $\varnothing$ ) qui décrit l'évolution des quantités résiduelles en tenant compte de trois paramètres: une fraction non dégradable, QNDFnd $_{\varnothing}$ ou QADFnd $\varnothing$, un taux de dégradation constant, $\mathrm{c}_{\varnothing} \mathrm{NDF}$ ou $\mathrm{c}_{\varnothing} \mathrm{ADF}$, et une fraction dégradable,

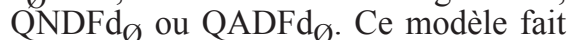
l'hypothèse qu'il n'y a ni fraction soluble ni temps de latence au début de la dégradation des constituants pariétaux.

- Le modèle proposé par Mertens (1973) (modèle M) qui a la même structure de base que le précédent. Cependant, il prend en compte une phase de latence progressive avec une augmentation au cours du temps du taux de dégradation, $\mathrm{c}(\mathrm{t})$, qui atteint une valeur asymptotique, $\mathrm{c}_{\mathrm{M}}$, avec un taux de croissance $\mathrm{d}_{\mathrm{M}}$. Ce modèle présente une allure générale sigmoïde.

Les équations relatives à ces deux modèles sont présentées dans l'encadré 1 (équations 1 et 2 , et 3 à 5 ).

Dans le cas du critère ADL, en raison de la faible quantité récupérée dans les sachets, seuls 198 échantillons ont pu faire l'objet d'une interprétation des cinétiques de dégradation. Une grande variabilité des valeurs QADL(t) a été observée pour un même échantillon d'un temps d'incubation à l'autre, notamment pour les aliments à faible teneur en ADL. Soixante échantillons (16 aliments) seulement ont présenté une évolution curvilinéaire nette au cours du temps et ont pu faire l'objet d'un ajustement individuel par le modèle $\varnothing$. Pour les autres échantillons $(n=138)$ présentant des évolutions erratiques dans le temps, une analyse de variance a été appliquée sur les valeurs QADL $(\mathrm{t})$ permettant de prendre en compte un effet échantillon et un effet linéaire et quadratique du temps. L'ensemble des résidus QADL(t) intraéchantillon ont ensuite été ajustés globalement par le modèle $\varnothing$ et un taux de dégradation unique a été retenu $\left(0,056 \mathrm{~h}^{-1}\right)$. Pour ces échantillons, la quantité d'ADL non dégradé (QADLnd, en $\% \mathrm{MS}$ ) a été estimée en considérant la valeur minimale des résidus obtenue après $24,36,48$ ou $72 \mathrm{~h}$ d'incubation.

Pour chaque constituant, les proportions des fractions dégradables et indégradables ont été exprimées en pourcentage de leur teneur initiale dans l'aliment (respectivement NDFdeg, ADFdeg, ADLdeg et NDFind, ADFind, ADLind, en \%).

La dégradabilité théorique (DT, en \%) de chaque constituant a été calculée en supposant que la probabilité pour une particule d'être encore présente dans le rumen au temps $t$ suivait une cinétique $\mathrm{du}$ premier ordre $\mathrm{F}(\mathrm{t})=\mathrm{e}^{-\mathrm{kp}_{\mathrm{t}}}$ avec un taux de sortie des particules du rumen constant, $\mathrm{k}_{\mathrm{p}}=0,06 \mathrm{~h}^{-1}$ (Vérité et al 1987) (encadré 1, équation 6) :

- pour le modèle $\varnothing$, le taux de dégradation constant permet une intégration algébrique simple de cette équation et la DT du NDF et de l'ADF a été calculée à partir de la proportion de la fraction dégradable (\% D) et des taux $\mathrm{c}_{\varnothing}$ et $\mathrm{k}_{\mathrm{p}}$ (encadré 1, équation 7).

- dans le cas du modèle $M$, la différentielle de $\mathrm{Qd}(\mathrm{t})$ inclut un taux de dégradation qui varie avec le temps (équation 8 , encadré 1). La nouvelle fonction $\mathrm{G}(\mathrm{t})$ ne pouvant pas être intégrée facilement, la DT a donc été calculée par intégration numérique de $\mathrm{t}=0$ à $\mathrm{t}=300 \mathrm{~h}$ en utilisant un pas de temps court ( $\mathrm{Dt}=0,25 \mathrm{~h}$ ) (équation 9, encadré 1).

\section{c) Calculs des relations entre para-} mètres

Pour chaque échantillon, les ajustements par les deux modèles ont été comparés et le modèle présentant le plus faible écart-type résiduel a été conservé. Pour chaque aliment, les valeurs moyennes des différents paramètres de dégradation des constituants pariétaux ont été calculées pour les deux modèles à partir des échantillons les mieux ajustés par chacun d'entre eux.

Les analyses statistiques et l'étude des relations entre les paramètres issus des deux modèles d'ajustements (encadré 2) et les critères de composition chimique ont été réalisées par régressions linéaires simples ou multiples et par analyse de covariance en tenant compte d'un effet aliment (procédures PROC REG et PROC GLM de SAS, 2000).

Une analyse de variance a également été appliquée avec la procédure GLM (SAS 2000) sur le ratio (Y/X) entre les quantités de parois non dégradées $\left(\right.$ QNDFnd $_{\mathrm{M}}$ en \% MS) $(=\mathrm{Y})$ et les teneurs ADL $(\% \mathrm{MS})(=\mathrm{X})$ des aliments afin de détecter l'influence de leur origine botanique ou technologique. Afin de donner un poids différent à chaque aliment selon leurs teneurs en ces constituants, la distance de chaque point à l'origine du plan $\left[\right.$ dist $\left.=\left(\mathrm{Y}^{2}+\mathrm{X}^{2}\right)^{1 / 2}\right]$ a été utilisée dans une variable de pondération $\mathrm{W}=$ dist/moyenne(dist). Cette analyse de variance a permis de regrouper statistiquement sur la base de ce ratio les différents types de matières premières, d'abord au sein de chaque famille d'aliments de même origine botanique ou technologique (céréales, racines et tubercules, coproduits de graines oléagineuses ou de palmiers...) et ensuite sur l'ensemble des groupes réunis.

Enfin, pour 33 aliments, les valeurs moyennes des paramètres de dégradation du NDF issues de cette étude ont été comparées à celles publiées par différents auteurs dans la bibliographie $(n=10)$. Les différences observées sur ces paramètres ont fait l'objet d'une analyse de variance-covariance pour tester un éventuel effet «référence bibliographique». 
Encadré 1. Les équations relatives aux ajustements des cinétiques de dégradation.

\section{Equations des modèles}

Modète

$\mathrm{QNDF}(\mathrm{t})=\mathrm{QNDFnd}_{\varnothing}+\mathrm{QNDFd}_{\varnothing} \times \mathrm{e}^{-\mathrm{C}_{ø \mathrm{NDF}} \mathrm{t}}$

(Équation 1)

$\mathrm{QADF}(\mathrm{t})=\mathrm{QADFnd}+\mathrm{QADFd}_{\kappa} \times \mathrm{e}^{-\mathrm{C}_{ø \mathrm{ADF}} \mathrm{t}}$

(Équation 2)

Modèle $M$ :

$\mathrm{c}(\mathrm{t})=\mathrm{c}_{\mathrm{M}}\left(1-\mathrm{e}^{-\mathrm{d}_{\mathrm{M}} \mathrm{t}}\right)$

$\mathrm{QNDF}(\mathrm{t})=\mathrm{QNDFnd}_{\mathrm{M}}+\mathrm{QNDFd}_{\mathrm{M}} \times \mathrm{e}^{-\mathrm{c}_{\mathrm{M}} \mathrm{NDF}}\left(1-\mathrm{e}^{-\mathrm{d}_{\mathrm{M}} \mathrm{NDF}} \mathrm{t}\right) \mathrm{t}$

(Équation 3)

$\left.\mathrm{QADF}(\mathrm{t})=\mathrm{QADFnd}_{\mathrm{M}}+\mathrm{QADFd}_{\mathrm{M}} \times \mathrm{e}^{-\mathrm{c}_{\mathrm{M}^{A D F}}\left(1-\mathrm{e}^{-\mathrm{d}_{\mathrm{M}} A D F} \mathrm{t}\right.}\right) \mathrm{t}$

\section{Calcul de la DT}

$\mathrm{DT}=100-\int_{0}^{\infty} \operatorname{diff}[\mathrm{Qd}(\mathrm{t})] \times \mathrm{F}(\mathrm{t}) \mathrm{dt}=100-\int_{0}^{\infty} \mathrm{G}(\mathrm{t}) \mathrm{dt}$

avec Qd(t): quantité du constituant dégradable non encore dégradé au temps $\mathrm{t}$

et $\quad \mathrm{G}(\mathrm{t})=$ différentielle de $[\mathrm{Qd}(\mathrm{t})] \times \mathrm{F}(\mathrm{t})$

Modèle Ø :

$\mathrm{DT}_{\varnothing}=\% \mathrm{D}_{\varnothing} \times \frac{\mathrm{c}_{\varnothing}}{\mathrm{c}_{\varnothing}+\mathrm{k}_{\mathrm{p}}}$

(Équation 7)

Modèle $M$ :

$$
\begin{aligned}
& \operatorname{diff}[Q d(t)]=Q d \times\left(-c_{M} d_{M} t^{-d_{M} t}-c_{M}\left(1-e^{-d_{M} t}\right)\right) \times e^{-c_{M}\left(1-e^{-d_{M} t}\right) t} \\
& D^{T}=100-\sum_{0}^{300}\left[\frac{G\left(t_{i}\right)+G\left(t_{i-1}\right)}{2}\right] \times\left(t_{i}-t_{i-1}\right)
\end{aligned}
$$

(Équation 8)

(Équation 9)

\section{2 / Résultats}

\section{1 / Composition chimique des aliments}

La composition chimique moyenne des aliments (moyennes et écarts types) est précisée dans l'annexe 1. Pour des raisons de lisibilité du tableau, seules les valeurs relatives aux matières premières y sont présentées.

Sur l'ensemble des échantillons de tous les aliments, les teneurs en constituants pariétaux ont varié dans de larges plages : de 0,8 à $85,1 \%$ MS pour NDF (moyenne $\pm \mathrm{ET}=36,5 \pm 21,2 \%$ $\mathrm{MS})$, de 0,2 à $67,2 \% \mathrm{MS}$ pour $\mathrm{ADF}$
$(21,6 \pm 16,9 \% \mathrm{MS})$ et de 0 à $54,5 \%$ MS pour ADL $(7 \pm 11 \% \mathrm{MS})$. Les variations inter- et intra-aliment observées ici sont représentatives des aliments communément employés dans l'alimentation des ruminants. Elles sont en accord avec les valeurs publiées par Belyea et al (1989) ou Arosemena et al (1995) et avec les données des tables récentes (Sauvant et al 2004, INRA 2007) et celles collectées dans la base de données io (AFZ 2010). Ceci permet une validation satisfaisante des résultats présentés ici.

La composition des parois des aliments peut être appréciée par les ratios calculés entre les teneurs des différentes fractions. Ainsi, le ratio NDF/ADF des échantillons a fortement varié, de 1 à 5 environ, autour d'une valeur moyenne de 2,2 $\pm 0,9$ et est largement influencé par l'origine botanique (ET interaliments $=2,0, \mathrm{ddl}=40, P<0,001)$. Il est compris entre 3 et 4 dans le cas des céréales et leurs coproduits, tandis qu'il est inférieur à 2 pour les graines oléagineuses et protéagineuses et leurs coproduits ainsi que pour les plantes entières et les divers coproduits de racines et tubercules. Les relations entre NDF et $\mathrm{ADF}$ et plus particulièrement entre $\mathrm{ADF}$ et ADL ne sont pas linéaires. La relation entre ces derniers montre que pour les matières premières qui ont des teneurs en $\mathrm{ADL}>8 \% \mathrm{MS}$ les variations de teneurs en ADF sont essentiellement 
dues à une augmentation de la quantité de lignine. De plus, il n'y a pas de relation entre la quantité d'hémicellulose, estimée par la différence NDF-ADF et la quantité de cellulose, estimée par la différence ADF-ADL. Cependant, le ratio hémicellulose/cellulose semble souvent supérieur à 2 pour les produits de céréales, tandis qu'il est proche de 0,5 pour les graines oléagineuses et protéagineuses. Les pulpes de betterave et les tourteaux exotiques (palmiste, coprah et coton) présentent des ratios intermédiaires proches de 1 . Par ailleurs, une forte proportion de constituants pariétaux lignifiés est observée dans certains aliments comme les enveloppes de graines, les pulpes de tomate et les coproduits du raisin.

\section{2 / Etude des paramètres de dégradation des constituants pariétaux}

\section{a) Les paramètres de dégradation $d u$ $N D F$}

Les valeurs moyennes des paramètres de dégradation du NDF des aliments issus des deux modèles sont présentées dans l'annexe 2. Pour des raisons de lisibilité, seules les données relatives aux matières premières sont présentées dans les annexes 2, 3 et 4 .

Sur l'ensemble des échantillons de tous les aliments, la fraction dégradable $\left(\mathrm{QNDFd}_{\mathrm{M}}\right.$, en $\left.\mathrm{MS}\right)$ a varié de 0,7 à 64,9\% MS autour d'une moyenne de $23,9 \pm 14,2 \%$ MS. La fraction non dégradable (QNDFnd ${ }_{M}$ ) a varié entre 0 et $70 \%$ MS $(12,8 \pm 15,7 \% \mathrm{MS})$, mais la majorité des échantillons étudiés ont des valeurs QNDFnd ${ }_{M}$ inférieures à 20-25\% MS. Plus les teneurs en ADF ou ADL des échantillons sont élevées plus la fraction NDF non dégradée est importante. Cependant, les relations entre QNDFnd ${ }_{M}$, d'une part, et ADF ou ADL, d'autre part, étudiées de façon globale, montrent des précisions voisines et relativement faibles :

QNDFnd $_{\mathrm{M}}=-3,94( \pm 0,90)+0,78( \pm 0,03) \mathrm{ADF}$ $($ Nech $=217$, Rglobal $=0,85$, ETRglobal $=8,1)$ QNDFnd $_{\mathrm{M}}=4,40( \pm 0,64)+1,21( \pm 0,05) \mathrm{ADL}$

$($ Nech $=217$, Rglobal $=0,85$, ETRglobal $=8,0)$.

Les différences importantes observées sur les paramètres de dégradation des diverses matières premières peuvent être expliquées par la variabilité de qualité des constituants pariétaux entre les aliments étudiés. En effet, les valeurs d'ETR observées pour ces relations sont largement expliquées par un effet aliment. Par exemple, pour une même teneur en $\mathrm{ADF}$, le très faible ratio lignine/cellulose des coques de soja explique

\section{Encadré 2. Comparaison des paramètres issus des deux modèles}

La comparaison des paramètres des ajustements réalisés par les deux modèles sur l'ensemble des échantillons de tous les aliments montre que l'utilisation du modèle $\varnothing$ conduit à des écarts types résiduels (ETR) légèrement plus faibles que ceux obtenus par le modèle $\mathrm{M}$ quand les cinétiques de dégradation ne montrent pas de phase de latence. Dans ces cas, le modèle $M$ montre un surparamétrage et l'estimation du paramètre $d_{M}$ est souvent imprécise. A l'inverse, pour les aliments qui montrent une phase de latence (pulpe de betterave, maïs et coproduits, tourteau de soja tanné...), les ajustements avec le modèle $\varnothing$ ont toujours des ETR plus élevés que ceux observés avec le modèle M. L'amélioration des ETR apportée par le modèle $M$ par rapport au modèle $\varnothing$ pour les cinétiques à phase de latence est en général plus importante mais aussi plus variable que celle obtenue en utilisant le modèle $\varnothing$ au lieu du modèle $M$ pour les cinétiques sans latence $(\Delta E T R=1,0 \pm$ $1,0$ vs. $0,25 \pm 0,30)$.

Les estimations des fractions dégradées (QNDFd, QADFd) et non dégradées (QNDFnd, QADFnd) obtenues à partir des deux modèles d'ajustement sont très corrélées entre elles:

QNDFd $_{M}=2,31( \pm 0,43)+0,83( \pm 0,01)$ QNDFd $_{\varnothing} \quad($ Nech $=216$, Rglobal $=0,97$, ETRglobal $=3,4)$ QNDFnd $_{M}=3,23( \pm 0,38)+0,92( \pm 0.02)$ QNDFnd $_{\varnothing}($ Nech $=202$, Rglobal $=0,85$, ETRglobal $=4,4)$ $\operatorname{QADFd}_{M}=0,99( \pm 0,25)+0,84( \pm 0,01)$ QADFd $\varnothing \quad($ Nech $=212$, Rglobal $=0,97$, ETRglobal $=2,1)$ QADFnd $_{M}=1,45( \pm 022)+0,97( \pm 0,01)$ QADFnd $\varnothing \quad($ Nech $=203$, Rglobal $=0,98$, ETRglobal $=2,6)$.

Cependant, l'ajustement par le modèle $\varnothing$ des fractions non dégradées qui présentent une phase de latence importante conduit à une surestimation de la fraction dégradable et par conséquent à une sous-estimation de la fraction non dégradable, qui devient même négative dans certaines de nos données. Par voie de conséquence, cette surestimation de la fraction dégradable génère artificiellement des fractions «solubles» négatives pour les constituants pariétaux. Cet aspect a déjà été mentionné par McDonald (1981). Les résultats des ajustements réalisés par le modèle $\varnothing$ sur les cinétiques de dégradation du NDF publiés par DePeters et al (1997), conduisent également à des valeurs de fractions «solubles» négatives, notamment pour les pulpes de betterave $(-8,5 \%)$ et d'agrumes $(-25,3 \%)$, qui présentent toutes les deux une phase de latence. Par conséquent, les fractions dégradables estimées par le modèle $M$ sont toujours plus faibles que celles obtenues avec le modèle $\varnothing$, tandis que la hiérarchie entre ces deux modèles est inversée pour les fractions non dégradables.

Le taux de dégradation $C_{M}$ évalué par le modèle $M$ est toujours supérieur à celui $\left(c_{\varnothing}\right)$ issu du modèle $\varnothing$. Néanmoins, ces deux paramètres n'ont pas la même signification. Le paramètre $c_{\varnothing}$ reste constant au cours du processus de dégradation. Le paramètre $c_{M}$ du modèle $\mathrm{M}$ représente la valeur maximale du taux de dégradation $\mathrm{c}(\mathrm{t})$, qui est atteinte après un temps infini pour une fraction dégradable infiniment faible.

Dans cette étude, les valeurs du taux de dégradation maximum $\mathrm{c}_{\mathrm{M}}$ obtenues pour certaines matières premières sont élevées $\left(>0,15 \mathrm{~h}^{-1}\right)$. Les ajustements des cinétiques de dégradation du NDF des pulpes de betterave et de citrus obtenus par DePeters et al (1997) avec le modèle de McDonald (1981), qui intègre un temps de latence discret, conduisent également à des valeurs de taux de dégradation très élevées (en moyenne 0,23 et $0,38 \mathrm{~h}^{-1}$, respectivement) comparativement aux valeurs $c_{\varnothing}$ publiées par ces auteurs. De même, dans l'étude de Sauvant et al (1986a et b), certains aliments à paroi digestible (tourteaux de coprah et de palmiste, lupin, pulpe de betterave, coques de soja) présentent également des valeurs $c_{M}$ particulièrement élevées pour la même raison que celle évoquée ci-dessus. Dans notre étude, le nombre important d'aliments permet de mettre en évidence que les valeurs de $c_{M}$ sont plus fortes quand la phase de latence est plus importante, c'est-à-dire quand les valeurs de $d_{M}$ sont plus faibles. Ceci démontre la faible accessibilité initiale des constituants pariétaux et une accélération des processus de dégradation une fois que la phase de latence est passée. Cette phase de latence a été décrite comme une étape d'hydratation des particules et de colonisation par les microorganismes (Latham 1980, Yang 1991). De plus, il est probable que les constituants, en raison des processus d'imbibition et de colonisation, passent progressivement par différentes phases correspondant à des structures qui sont de plus en plus dégradables par les microorganismes. La dégradation de tels constituants, alors fragilisés vis-à-vis de l'attaque microbienne, est ensuite facilitée et peut avoir lieu après la phase de latence, selon un processus de premier ordre et avec une vitesse plus élevée.

La comparaison des deux modèles peut montrer pour certains aliments de sérieuses distorsions sur chaque paramètre pris séparément. Cependant, ces paramètres ne sont pas indépendants les uns des autres et les biais observés pour chacun d'entre eux sont compensés partiellement dans le critère synthétique de DT. Ainsi, sur l'ensemble des échantillons de cette étude, les valeurs DT calculées pour les deux modèles sont très corrélées, bien que les valeurs soient légèrement plus faibles pour le modèle $M$ comparativement au modèle $\varnothing$ :

DTNDF $_{M}=-0,53( \pm 0,52)+0,93( \pm 0,01)$ DTNDF $_{\varnothing} \quad($ Nech $=216, \mathrm{R}=0.98, \mathrm{ETR}=2,7)$

Par ailleurs, les relations entre paramètres établies pour les deux modèles sur les valeurs moyennes par aliment sont très semblables à celles calculées à partir des mesures individuelles par échantillon. 
les plus faibles valeurs $\mathrm{QNDFnd}_{\mathrm{M}}$ pour ces échantillons comparativement au tourteau de palmiste ou à la pulpe de tomate. Dans le cas de la relation entre QNDFnd $_{M}$ et ADL, les échantillons de coques de tournesol et d'arachide, de paille de blé et de grignon d'olive s'éloignent de la relation générale avec une fraction QNDFnd ${ }_{M}$ particulièrement élevée en regard de leur teneur en lignine.

Dans cette étude, le nombre important d'ingrédients représentés par plusieurs échantillons a permis de calculer des relations intra-aliment. Par rapport aux relations globales, la précision de la prédiction de $\mathrm{QNDFnd}_{\mathrm{M}}$ par ces relations intra est largement améliorée (ETRintra $=2,1$ et 2,5 pour l'ADF et l'ADL respectivement).

Ainsi, la relation intra avec l'ADL : QNDFnd $_{\mathrm{M}}=-6,31( \pm 0,65)+1,11( \pm 0,09)$ ADL $($ Nech $=216$, Nalim $=88$, Rintra $=0,74$, ETRintra $=2,5$ ) montre qu'en moyenne la fraction NDF non dégradable varie entre les échantillons d'un même aliment à peu près dans les même proportions que leur teneur en ADL. Cependant, le poids de la fraction lignine sur la fraction non dégradable du NDF n'est pas le même selon les aliments et dépend de leur origine botanique. Quand les régressions sont calculées pour chacune des familles d'aliments, les pentes apparaissent assez différentes suivant les

Tableau 1. Relations entre la quantité de NDF non dégradée (modèle M) et la teneur en $A D L$ calculées par famille d'aliments.
Fruits et coproduits :
QNDFnd $_{M}=1,16( \pm 0,02) \mathrm{ADL}$
Légumineuses et Protéagineux :
QNDFnd $_{M}=4,72( \pm 0,89)+2,34( \pm 0,06)$ ADL $\quad($ Nech $=32, \mathrm{R}=0,99$, ETR $=3,0)$
Coproduits d'oléagineux :
QNDFnd $_{M}=2,34( \pm 0,13) \mathrm{ADL}$
Coproduits de palmiers :
QNDFnd $_{M}=1,53( \pm 0,10) \mathrm{ADL}$
Céréales et coproduits :
QNDFnd $_{M}=5,85( \pm 0,15)$ ADL

$$
\begin{aligned}
& (\text { Nech }=22, \mathrm{R}=0,96, \mathrm{ETR}=5,6) \\
& (\text { Nech }=32, \mathrm{R}=0,99, \mathrm{ETR}=3,0) \\
& (\text { Nech }=27, \mathrm{R}=0,85, \mathrm{ETR}=14,1) \\
& (\text { Nech }=14, \mathrm{R}=0,89, \mathrm{ETR}=3,8) \\
& (\text { Nech }=48, \mathrm{R}=0,95, \mathrm{ETR}=3,4)
\end{aligned}
$$

origines et la précision est améliorée (tableau 1).

Sur les 200 échantillons de matières premières, pour lesquels la fraction indégradable du NDF est estimée par le meilleur des deux modèles, soit le modèle M (97 échantillons) soit le modèle $\varnothing$ (103 échantillons), le ratio QNDFnd/ADL a varié de 0,4 à 12,7 . Selon les valeurs de ce ratio, cinq groupes statistiquement différents ont été identifiés. L'origine botanique et le type d'aliments expliquent largement ces variations (tableau 2). En effet, si le ratio QNDFnd/ADL est d'environ 1,2 pour divers coproduits de racines et pour les tourteaux de coprah, palmiste et coton, il est compris entre 2 et 3 pour les tourteaux de lin, arachide, colza et tournesol, tandis qu'il varie de
4 à plus de 8 pour les céréales et leurs coproduits (figure 2).

Sauvant et al (1986b) ont montré sur 24 matières premières que la quantité de NDF non dégradé après 48 h d'incubation (plus ou moins représentative de la fraction non dégradable) variait entre aliments avec leur teneur en ADL, selon une pente de 1,95. Dans le système de Cornell, Sniffen et al (1992) ont utilisé un coefficient de 2,4 pour calculer la quantité de glucides de structure indégradables à partir de la teneur en lignine des aliments. A la lumière des résultats présentés ici, cette valeur constante de 2,4 est discutable.

Ainsi, de nombreuses analogies sont

\begin{tabular}{|c|c|c|c|c|c|c|c|}
\hline \multirow{2}{*}{ Groupes } & \multirow{2}{*}{ N } & \multirow{2}{*}{ Familles } & \multirow{2}{*}{ Aliments } & \multicolumn{2}{|c|}{ QNDFnd/ADL } & \multicolumn{2}{|c|}{ Distance $^{1}$} \\
\hline & & & & Ism & sem & Ism & sem \\
\hline \multirow{4}{*}{1} & \multirow{4}{*}{49} & Racines & $\begin{array}{l}\text { Marc Chicoré, Carotte, } \\
\text { Artichaut Jérusalem, } \\
\mathrm{CP}^{2} \text { Pommes de terre, Salsifis }\end{array}$ & \multirow{4}{*}{1,21} & \multirow{4}{*}{0,11} & \multirow{4}{*}{28,4} & \multirow{4}{*}{2,5} \\
\hline & & Palmiers & $\begin{array}{l}\text { T. Coprah et Palmiste, } \\
\text { Noyau Datte }\end{array}$ & & & & \\
\hline & & Fruits & $\begin{array}{l}\text { CP Raisin, Pulpe Citrus, } \\
\text { Pomme et Tomate }\end{array}$ & & & & \\
\hline & & Divers & $\begin{array}{l}\text { CP Epinard, Gr. Soja/Colza } \\
\text { extrudée }\end{array}$ & & & & \\
\hline 2 & 23 & Graines Oléagineuses & CP Colza, Coton, Lin et Olive & 1,96 & 0,20 & 18,4 & 3,7 \\
\hline \multirow{6}{*}{3} & \multirow{6}{*}{70} & Racines & Pulpe Betterave & \multirow{6}{*}{3,06} & \multirow{6}{*}{0,14} & \multirow{6}{*}{12,6} & \multirow{6}{*}{2,1} \\
\hline & & Fruits & Ecorce Orange & & & & \\
\hline & & $\begin{array}{l}\text { Légumineuses } \\
\text { et Légumes } \\
\text { verts }\end{array}$ & $\begin{array}{l}\text { CP Arachide et Lupin, } \\
\text { CP Pois et Soja, Luzerne } \\
\text { CP Petit Pois et Haricots verts }\end{array}$ & & & & \\
\hline & & Graines Oléagineuses & CP Tournesol & & & & \\
\hline & & Divers & Levures & & & & \\
\hline & & Céréales & DDG Sorgho, Drêches brasserie & & & & \\
\hline 4 & 52 & Céréales & $\begin{array}{l}\text { Blé et CP, } \\
\text { Sorgho, Maïs et CP } \\
\text { Paille Avoine et Blé, Foin } \\
\text { Fétuque }\end{array}$ & 4,01 & 0,23 & 8,0 & 2,4 \\
\hline 5 & 16 & Céréales & Avoine, Ensilage Maïs & 8,5 & 0,51 & 11,1 & 7,2 \\
\hline
\end{tabular}
observées entre les constituants appartenant à une même famille végétale ou un

Tableau 2. Variation du ratio $Y / X$ entre les teneurs en $Q N D F n d M(Y)$ et $A D L(X)$ (en \% MS) selon les groupes d'aliments.

1 Distance $=\left(Y^{2}+X^{2}\right)^{1 / 2}$ servant de variable de pondération dans l'analyse de variance (voir texte).

Ism : moyennes ajustées par les moindres carrés ; sem : erreur type de la moyenne ajustée ; ${ }^{2} \mathrm{CP}=$ Coproduits. 
Figure 2. Influence de la teneur en $A D L$ sur la quantité de NDF non dégradée (modèle $M$ ).

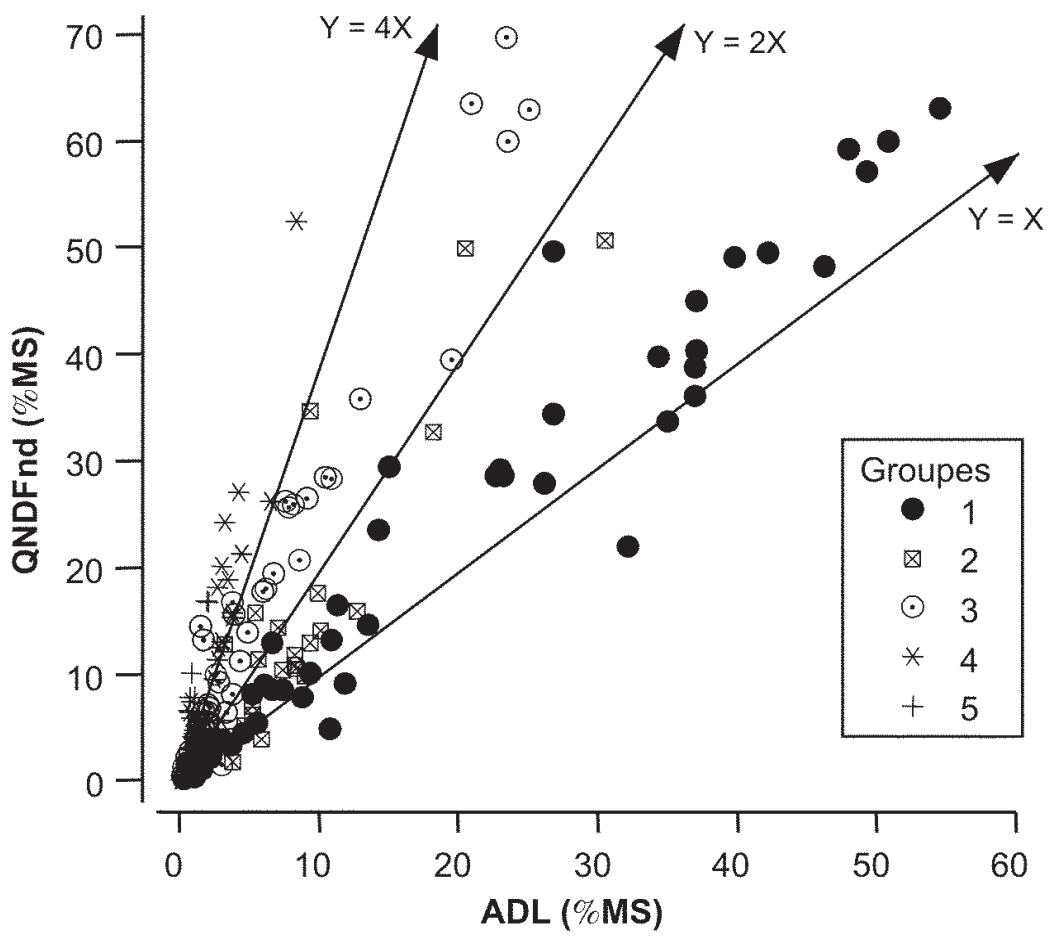

1 Groupes : cf. tableau 2.

même organe botanique. La proportion de NDFind (en \% NDF) est particulièrement élevée $(\geq 70 \%)$ dans le cas des enveloppes de graines oléagineuses (sauf les coques de soja), les grignons d'olives, les pelures de pommes de terre et les coproduits du raisin. La proportion de NDFind peut être importante dans des organes jouant un rôle de protection de la graine. Certains sont beaucoup plus riches en lignine ou autres constituants indigestibles, non mesurés dans cette étude (cutine ou silice, tannins...) (Thivend 1981, Van Soest 1982), que les parties internes de ces graines (enveloppes vs tourteau pour les graines oléagineuses, son vs grain pour le blé...). A l'inverse, la fraction NDFind est beaucoup plus faible $(\leq 25 \%)$ pour les coproduits de citrus, pulpe de betterave, maïs ou protéagineux et leurs coproduits, tourteaux de coprah et palmiste, légumes verts (épinards et haricots verts) et toutes les racines et tubercules (carottes, marc de chicorée, pomme de terre, salsifis, topinambour). Ceci confirme le caractère hautement digestible des parois de ces aliments (Sauvant 1981) et explique leur bonne valeur énergétique malgré une teneur importante en parois végétales (Sauvant et al 2004).

La comparaison de nos données moyennes avec celles de la bibliographie pour les mêmes aliments montre que nos résultats sont en très bon accord $(\mathrm{R}=0,95$ et 0,97 pour

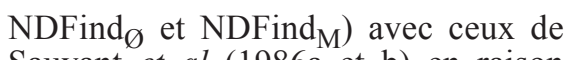
Sauvant et al (1986a et b) en raison sans doute de la similitude des méthodologies utilisées par les deux équipes lors des mesures in situ. Par contre, la comparaison est nettement moins bonne avec les résultats des autres équipes : $\mathrm{R}=0,64,0,66,0,63$ pour NDFind $_{\varnothing}$ et $\mathrm{R}=0,92,0,71,0,50$ pour NDFind $_{M}$ respectivement avec les résultats moyens de DePeters et al (1997), de Tamminga et al (1990) et de Varga et Hoover (1983). Ces moins bonnes concordances peuvent s'expliquer en partie par les quelques valeurs NDFind négatives que nous avons obtenues pour le pois, le soja et le maïs et certains de ses sous-produits. Cependant, Varga et Hoover (1983) proposent des valeurs NDFind étonnamment fortes (47 à 62\%) pour les coques de soja, le maïs et ses sous-produits (gluten meal, gluten feed), tandis que les données de Taminga et al (1990) sont plus élevées que les nôtres pour les tourteaux de palmiste et de coprah et au contraire plus faibles pour l'orge, l'avoine, le son de blé, le tourteau d'arachide et la pomme de terre.

Sur l'ensemble des échantillons, le taux de dégradation horaire de QNDFd varie largement, autour d'une moyenne de $c_{\varnothing}$ NDF $=0,077 \pm 0,047 \mathrm{~h}^{-1}$ et $\mathrm{c}_{\mathrm{M}^{\mathrm{NDF}}}=0,125 \pm 0,107 \mathrm{~h}^{-1}$. Les différences entre les taux de dégradation issus des deux modèles sont particulièrement importantes $\left(\mathrm{c}_{\mathrm{M}} \mathrm{NDF}-\mathrm{c}_{\overparen{Q}} \mathrm{NDF}\right.$ $\approx+0,1$ à $+0,5 \mathrm{~h}^{-1}$ ) pour les aliments ayant une phase de latence évidente (pulpe de betterave, marc de chicorée, pulpe de tomate, tourteau de coprah et de palmiste, pulpe de citrus) et qui présentent de très fortes valeurs $\mathrm{c}_{\mathrm{M}^{\mathrm{NDF}}}(0,2$ à $0,6 \mathrm{~h}^{-1}$ ) beaucoup plus élevées que $\mathrm{c}_{\varnothing \mathrm{NDF}}$. Le taux de croissance relatif de $\mathrm{c}_{\mathrm{M}}$ dans le modèle $\mathrm{M}, \mathrm{d}_{\mathrm{M}}$, présente des valeurs systématiquement supérieures à $0,20 \mathrm{~h}^{-1}$ pour les aliments qui montrent une phase de latence et dont les cinétiques de dégradation ont été mieux ajustées par ce modèle.

Les variations de taux de dégradation des constituants observées dans ce travail ne sont pas reliées à leur concentration dans les aliments, comme pour les autres paramètres. Cette absence de relation entre le taux de dégradation et la teneur du NDF des concentrés confirme nos conclusions antérieures à partir de données issues de la littérature (Chapoutot 1998). A l'inverse, Sauvant et al (1996), sur des données bibliographiques issues de mesures faites sur fourrages, ont montré une relation négative significative entre ces deux critères. D'un autre côté, aucune relation n'a été observée entre le temps de latence et les autres caractéristiques mesurées sur les aliments. Ces résultats ne vont pas dans le sens de ceux de Sauvant et al (1986a) qui ont montré sur un nombre plus faible d'aliments que le temps de latence augmentait proportionnellement avec la teneur en NDF dégradable des aliments.

La DT du NDF (DTNDF $_{M}=35,1$ $\pm 14,2 \%$ ) tend à diminuer quand la teneur en parois des aliments augmente mais la relation globale présente une faible précision $($ Rglobal $=0,24$, ETR $=13,0)$. Une relation négative légèrement plus précise apparaît entre $\mathrm{DTNDF}_{\mathrm{M}}$ et la teneur en ADL des aliments $($ Rglobal $=0,51$, ETR $=11,6)$ ou la proportion de constituants pariétaux lignifiés (ADL\% NDF) :

DTNDFM $=41,44( \pm 1,07)-0,46( \pm 0,05)$ ADL\%NDF

$($ Nech $=216, \mathrm{R}=0,53, \mathrm{ETR}=11,4)$.

Lorsqu'elle est étudiée intra-aliment, la relation présente des coefficients de régression assez voisins mais conduit à une meilleure précision (ETRintra = 4,5). La variabilité résiduelle de cette relation, qui est particulièrement importante pour les aliments à faible teneur en lignine, est partiellement expliquée par les différences de taux de dégradation du NDF observées entre aliments (par exemple pulpe de betterave $v s$ maïs et coproduits ou tourteau de soja) ou entre échantillons d'une même matière première.

Nous avons confronté nos résultats de DT du NDF aux valeurs recalculées de 
Figure 3. Comparaison des valeurs moyennes de dégradabilité théorique du NDF obtenues dans cette étude à celles issues de la bibliographie.

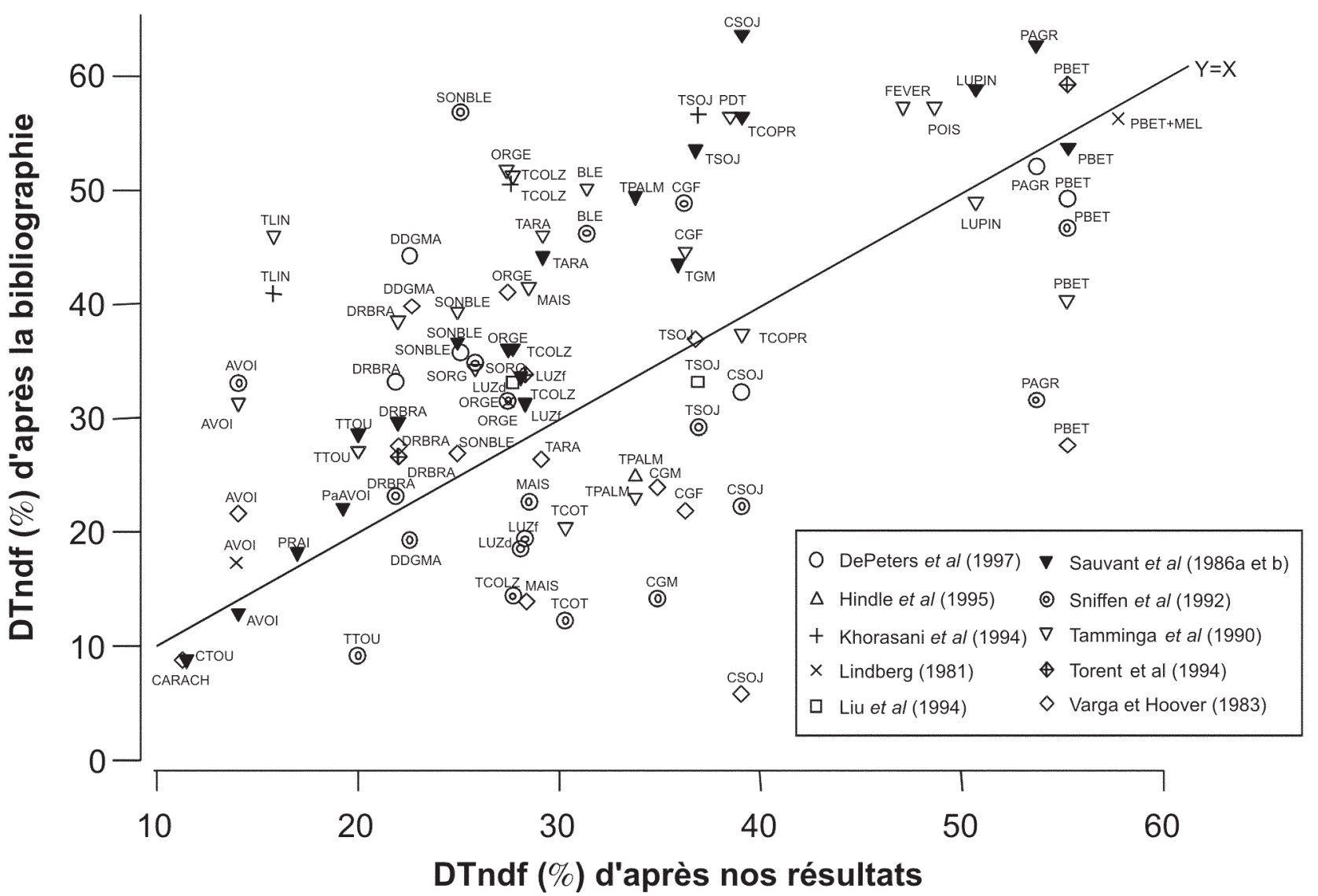

façon homogène à partir des paramètres publiés par les différents auteurs en tenant compte d'un taux de sortie des particules du rumen de $0,06 \mathrm{~h}^{-1}$ (Vérité et al 1987). Malgré le caractère plus synthétique de la DT qui «gomme» partiellement les écarts constatés sur chacun de ses déterminants, il apparaît une certaine hétérogénéité de résultats selon l'origine des données (figure 3). Ainsi, la majorité des valeurs DTNDF du système de Cornell (Sniffen et al 1992) apparaissent beaucoup plus faibles que nos résultats moyens, tandis qu'une grande partie des données publiées par Tamminga et al (1990) sont à l'inverse plus élevées. En revanche, il apparaît que les valeurs moyennes obtenues ici sont bien corrélées aux données publiées par Sauvant et al (1986a et b) $(\mathrm{R}=0,91)$, probablement en raison de la similitude des méthodologies employées pour les expériences in situ. La forte variabilité entre les résultats obtenus par différents auteurs peut être due à des différences de composition des aliments, mais dépend probablement aussi de la méthodologie utilisée pour les mesures in situ. Cette comparaison valide le travail réalisé ici sur un nombre plus important d'échantillons très divers et avec une méthodologie relativement homogène. De plus, cela confirme l'intérêt d'une standardisation de la méthode in situ, comme suggéré par Michalet-Doreau et al (1987) et la nécessité d'utiliser des aliments témoins qui permettent de corriger les effets essais ou laboratoires (Vérité et al 1990).

Exprimée en proportion du NDF dégradable, la part qui est réellement dégradée en tenant compte du taux de sortie des particules du rumen $\left(\mathrm{k}_{\mathrm{p}}=\right.$ $0,06 \mathrm{~h}^{-1}$ ) varie de 25 à $75 \%$. Ce ratio tend à diminuer quand $\mathrm{c}_{\mathrm{M}^{\mathrm{NDF}}}$ et $\mathrm{d}_{\mathrm{M}} \mathrm{NDF}$ diminuent $(\mathrm{Rglobal}=0,56$ et 0,38 respectivement, $n=107)$. La quantité de NDF théoriquement dégradée (exprimée en \% MS) ne représente qu'en moyenne $12 \pm 7,7 \%$ MS des aliments (de 0,2 à $34 \% \mathrm{MS}$ ). Pour les matières premières à forte teneur en NDF dégradable (QNDFd $\geq 20-25 \%$ MS) et dont les cinétiques de dégradation du NDF montrent une phase de latence (coproduits du maïs, drèches de brasserie, noyau de dattes, tourteau de coprah et palmiste, coques de soja et pulpe de betterave) l'écart entre les quantités de NDF théoriquement et potentiellement dégradables est important (figure 4). Cette réduction de la quantité de NDF théoriquement dégradée est évidemment plus marquée quand le flux de sortie des particules du rumen est plus rapide, par exemple pour les animaux à fort niveau de production.

b) Les paramètres de dégradation de l'ADF

Les valeurs moyennes des paramètres de dégradation de l'ADF estimés par les deux modèles sont présentées dans l'annexe 3 pour les aliments simples.

Comparés sur l'ensemble des échantillons, les paramètres de dégradation de l'ADF sont étroitement liés à ceux mesurés pour le NDF quel que soit le modèle utilisé (par exemple $\mathrm{R}=0,96$, $0,84,0,70$ respectivement pour la fraction non dégradable, la fraction dégradable et le taux de dégradation estimés par le modèle Ø).

Calculée sur tous les échantillons, la fraction non dégradée, QADFnd ${ }_{\mathrm{M}}$, est en moyenne de $9,6 \pm 13,6 \%$ MS et est reliée positivement à la teneur en $\mathrm{ADL}$ des aliments. Comme précédemment pour le NDF, la pente de la relation intra-aliment présentée ci-dessous est plus faible que celles des relations globales ou inter-aliments qui sont surestimées par un effet aliment :

QADFnd $_{\mathrm{M}}=4,55( \pm 0,60)+0,78( \pm 0,08) \mathrm{ADL}$ $(n=212$, Rintra $=0,65$, ETRintra $=2,3)$. 
Figure 4. Relation entre la quantité de NDF théoriquement dégradée et la teneur en NDF dégradable des aliments (modèle $M$ ).

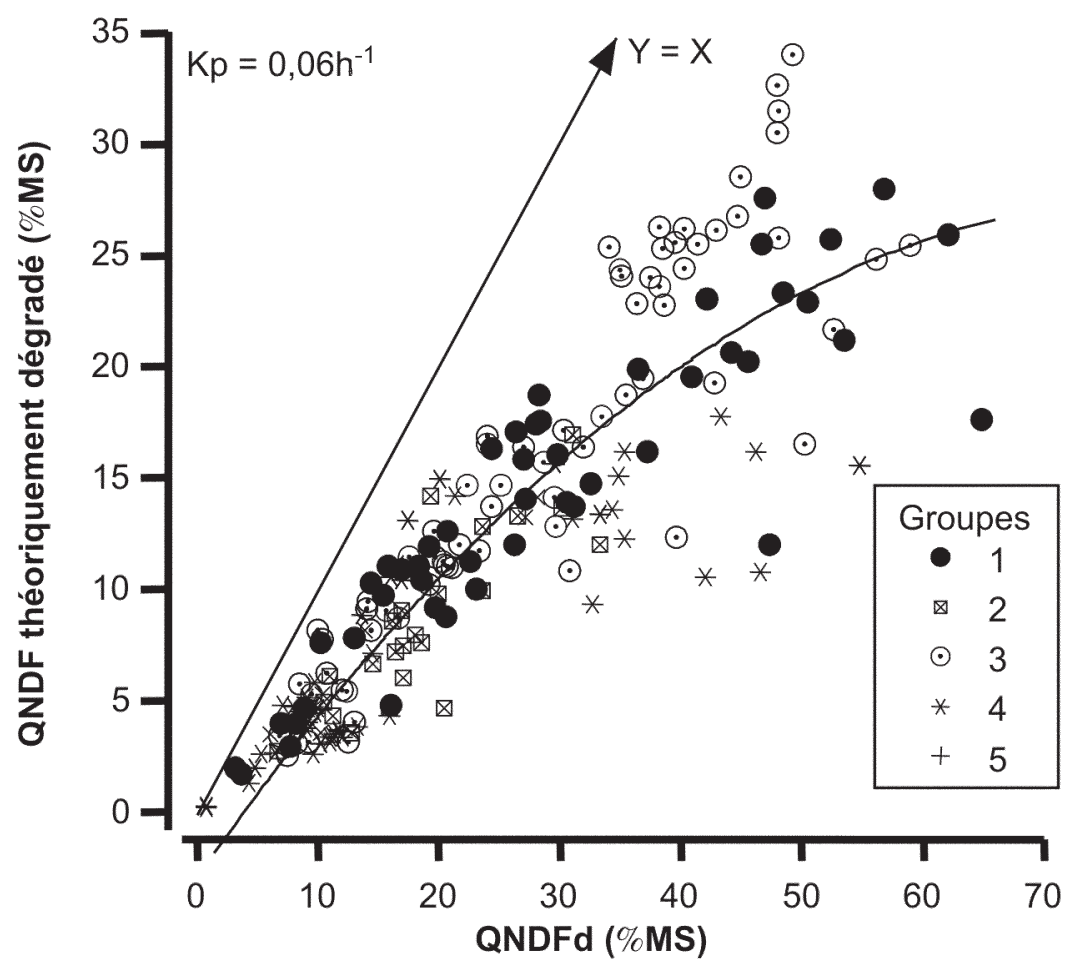

1 Groupes : cf. tableau 2.

La proportion d'ADFind (31,9 $\pm 28,5 \% \mathrm{ADF})$ est influencée positivement par la quantité de lignine contenue dans cette fraction (Rglobal $=0,69$, ETRglobal $=18,4$, ETRintra $=8,7)$.

De plus, la variation résiduelle de cette relation globale est fortement corrélée à celle observée pour la relation analogue dans le cas du NDF. Certains aliments, tels que les tourteaux et enveloppes d'oléagineux, la luzerne, les coproduits d'orge et de blé présentent une proportion très importante de NDFind et ADFind eu égard à la part lignifiée de leurs fractions NDF et ADF. Ces échantillons sortent du lot en raison de la quantité d'holocellulose (NDF-ADL) non dégradée qui est environ trois fois plus importante que la fraction de lignine non dégradable.

Sur l'ensemble des échantillons, le taux de dégradation horaire de la fraction QADFd estimé par le modèle $\varnothing$ $\left(\mathrm{c}_{\emptyset \mathrm{ADF}}=0,076 \pm 0,062 \mathrm{~h}^{-1}\right)$ apparaît pour la majorité des aliments inférieur à $0,20 \mathrm{~h}^{-1}$. Le taux de dégradation maximal $\mathrm{c}_{\mathrm{M}} \mathrm{ADF}$ obtenu par le modèle $\mathrm{M}$ est en moyenne plus élevé et plus variable que $\mathrm{c}_{\varnothing \mathrm{ADF}}\left(\mathrm{c}_{\mathrm{M}}^{\mathrm{ADF}}=0,119 \pm 0,120\right.$ $\mathrm{h}^{-1}$ ). Comme pour le NDF, les plus fortes valeurs de $\mathrm{c}_{\mathrm{M}} \mathrm{ADF}$ sont observées pour les aliments ayant une longue phase de latence. La relation entre les taux $\mathrm{c}_{\mathrm{M}}$ obtenus pour l'ADF et le NDF est moins bonne que celle observée pour $\mathrm{c}_{\varnothing}(\mathrm{R}=0,56$ vs 0,70$)$ : les échantillons de pulpe de betterave ont des valeurs $\mathrm{c}_{\mathrm{M}} \mathrm{ADF}$ plus fortes que la tendance générale et, à l'opposé, les échantillons de tourteaux de coprah et palmiste et de pulpe de tomate présentent des valeurs $\mathrm{c}_{\mathrm{M}}$ NDF plus élevées que la relation générale. Les valeurs de $d_{M} A D F$, en générale inférieures à $0,20 \mathrm{~h}^{-1}$ pour les échantillons à longue phase de latence, sont faiblement reliées à celle de $\mathrm{d}_{\mathrm{M}^{\mathrm{NDF}}}$ $(\mathrm{R}=0,44)$.

La DT de l'ADF $\left(\right.$ DTADF $_{\mathrm{M}}=31,1$ $\pm 15 \%)$ a varié entre 6 et $67 \%$ sur l'ensemble des aliments, ce qui correspond à une quantité de ADF théoriquement dégradée entre 0,4 à 17\% MS (moyenne : $6,2 \pm 4,5 \% \mathrm{MS}$ ) quand le transit des particules sortant du rumen est pris en compte $\left(\mathrm{k}_{\mathrm{p}}=0,06 \mathrm{~h}^{-1}\right)$. La DT de l'ADF diminue à mesure que la proportion d'ADL augmente dans l'ADF. Ce critère présente un effet significatif à travers un terme linéaire et un terme quadratique dans la relation intraaliment suivante, bien que la précision de cette relation reste assez faible :

$\mathrm{DT}_{\mathrm{M}} \mathrm{ADF}=42,63( \pm 5,14)-0,80( \pm 0,34)$ $\mathrm{ADL} \% \mathrm{ADF}+0,0072( \pm 0,0037)(\mathrm{ADL} \% \mathrm{ADF})^{2}$

$($ Nech $=212, \quad$ Nalim $=88, \quad$ Rintra $=0.27$, ETRintra $=5,2$ ).
Dans la bibliographie, peu d'auteurs ont décrit les valeurs des paramètres de dégradation de l'ADF en même temps que ceux du NDF. De plus, pour la plupart des études, les résultats ne concernent que les fourrages. Les paramètres de dégradation de l'ADF décrits ici sont très corrélés à ceux du NDF. Ceci est en accord avec la synthèse des données de la littérature que nous avons réalisée (Chapoutot 1998) à partir des résultats de Soofi et al (1983), Giger et al (1987), Sharma et al (1988), Tedesco et al (1990), Aronen et al (1991), Torrent et al (1994), Andrighetto et al (1995), Greppi et al (1995), McKinnon et al (1995), Tamburini et al (1995).

\section{3 / Les paramètres de dégrada- tion de I'ADL}

Sur l'ensemble des échantillons étudiés, la quantité d'ADL non dégradée, QADLnd, a varié de 0,1 à 49,2\% MS (moy $=5,6 \pm 9,9)$, avec des valeurs inférieures à $10 \%$ pour la plupart des aliments, d'environ 25 à $35 \%$ pour certaines enveloppes de graines (tournesol, colza et arachide) ou les pulpes de tomate et de raisin, et atteignant 50\% pour les pépins de raisin. Il apparaît une relation précise entre QADLnd et la teneur en ADL initiale des échantillons quand un effet «type d'aliment» est pris en compte $($ ddl $=82, \quad$ ET $=2,2$, $P<0,001)$ :

$$
\begin{aligned}
\text { QADLnd }=0,81( \pm 0,04) \text { ADL } \\
(\text { Nech }=198, \text { Nalim }=83, \text { Rintra }=0,91, \\
\text { ETRintra }=0,7) .
\end{aligned}
$$

Cette relation montre qu'en moyenne presque $20 \%$ de la lignine des aliments est «dégradée» dans le rumen lorsque cette mesure est effectuée par la méthode des sachets de Nylon. Cette proportion, qui reste constante d'une famille d'aliment à l'autre, rejoint les résultats de Giger (1985) qui a montré que la lignine, bien que généralement considérée comme indigestible in vivo, était en partie digérée dans l'ensemble du tube digestif.

Le taux relatif de dégradation de

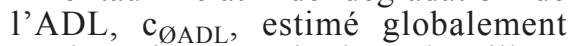
sur la majeure partie des échantillons est d'environ $5,6 \% / \mathrm{h}$. Dans le cas des aliments ayant pu être ajustés par le modèle Ø (annexe 4), il apparaît que ce taux peut être plus élevé pour certains aliments (coproduits du raisin, tourteau de coprah, luzerne déshydratée et coque de tournesol). 


\section{Conclusion}

Cette étude, conduite sur un grand nombre d'échantillons d'origines diverses, a démontré la grande variabilité des cinétiques de dégradation des constituants pariétaux des aliments concentrés et coproduits qui peuvent présenter des amplitudes de dégradation très différentes et des temps de latence plus ou moins marqués et a mis en évidence les principaux facteurs explicatifs des variations observées entre aliments. La quantité de constituants pariétaux indégrada- bles est très largement dépendante de la teneur en lignine des aliments. Néanmoins, l'influence de ce critère varie fortement d'une famille d'aliments à l'autre. La part de la fraction pariétale dégradable réellement valorisée par l'animal compte tenu du transit particulaire dans le rumen est plus faible pour les matières premières présentant une latence importante.

Ce travail a permis d'établir une table cohérente des paramètres moyens caractérisant la dégradation des constituants pariétaux sur près de 80 matières premières classiquement utilisées dans l'alimentation des ruminants. Ces données pourront contribuer à l'amélioration des systèmes d'unités d'alimentation ; elles pourront également être valorisées dans les travaux de modélisation de la digestion dans le rumen.

Enfin, la comparaison des résultats de ce présent travail et ceux de la littérature révèle l'hétérogénéité des données disponibles et confirme la nécessité de réaliser une synthèse plus complète de tous les jeux de données publiées concernant la dégradation des constituants pariétaux.

\section{Références}

AFZ, 2010. io - La banque de données de l'alimentation animale. Association Française de Zootechnie, Paris.

Andrighetto I., Cozzi G., Magni G., Hartman B., Hinds M., Sapienza D., 1995. Comparison of in situ degradation kinetics of lucerne germplasm by ANOVA of non-linear models. Anim. Feed Sci. Technol., 54, 287-299.

Apper-Bossard E., Peyraud J.L., Faverdin P., Meschy F., 2006. Changing dietary cationanion difference for dairy cows fed with two contrasting levels of concentrate in diets. J. Dairy Sci., 89, 749-760.

Archimède H., Sauvant D., Hervieu J. Poncet C., Dorléans M., 1995a. Digestive interactions in the ruminant: relationships between whole tract and stomach evaluation. Anim. Feed Sci. Technol., 54, 327-340.

Archimède H., Sauvant D., Dorléans M. Chapoutot P., Poncet C., 1995b. Influence of the nature of forage and concentrate on the digestive interactions measured in sacco and in vivo. Anim. Feed Sci. Technol., 54, 341-356.

Aronen A., Vanhatalo A., Varvikko T., 1991 Ruminal and intestinal degradation of cell wall constituents of barley, barley fibre and wheat mill run measured by the nylon bag technique. Anim. Feed Sci. Technol., 32, 201-205.

Arosemena A., DePeters E.J., Fadel J.G. 1995. Extent of variability in nutrient composition within selected by-product feedstuffs. Anim. Feed Sci. Technol., 54, 103-120.

Baumont R., Barlet A., Jamot J., 1996. L'effet d'encombrement ruminal des fourrages: sa relation avec l'ingestibilité et étude de sa prévision au laboratoire. Renc. Rech. Rum., 3, 313-316.

Belyea R.L., Stevens B.J., Restrepo R.J., Clubb, A.P., 1989. Variation in composition of by-product feeds. J. Dairy Sci., 72, 2339-2345.

Chapoutot P., 1998. Etude de la dégradation in situ des constituants pariétaux des aliments pour ruminants. Thèse Docteur en Sciences Agronomiques, Institut National Agronomique Paris-Grignon, Paris, France.

De Smet A.M., Boever J.L., Brabander D.L., Vanacker J.M., Boucque C.V., 1995. Investigation of dry matter degradation and acidotic effect of some feedstuffs by means of in sacco and in vitro incubations. Anim. Feed Sci. Technol., 51, 297-315.
DePeters E.J., Fadel J.G., Arosemena A., 1997. Digestion kinetics of neutral detergent fibre and chemical composition within some selected by-product feedstuffs. Anim. Feed Sci. Technol., 67, 127-140.

Dorléans M., 1985. Descriptif du mode opératoire de la méthode Van Soest adaptée à l'analyse des aliments concentrés. Cah. Techn. INRA, 11, 33-40.

Ellis W.C., Mahlooji M., Matis J.H, 2005 , Models for estimating parameters of neural detergent fiber digestion by ruminal microorganisms. J. Anim. Sci., 83, 1591-1601.

Fadel J.G., DePeters E.J., Arosemena A., 2000. Composition and digestibility of beet pulp with and without molasses and dried using three methods. Anim. Feed Sci. Technol., 85, 121-129.

Giger S., 1985. Revue sur les méthodes de dosage de la lignine utilisées en alimentation animale. Ann. Zootech., 34, 85-122.

Giger S., Thivend P., Sauvant D., Dorléans M., Journaix P., 1987. Étude de l'influence préalable de différentes enzymes amylolytiques sur la teneur en résidu NDF d'aliments du bétail. Ann. Zootech., 36, 39-48.

Goering H. K., Van Soest P. J., 1970. Forage fibre analysis. Agricultural Handbook. Report from R.R.S., USDA, Washington, DC., USA 379.

Greppi G.F., Liponi G.B., Nola R., Di Pasquale A.M., Pasquini M., 1995. Comparison of in situ rumen degradation of NDF and ADF by sheep and goats. Zoot. Nutr. Anim., 21, Suppl., 81-87.

Hindle V.A., Steg A., Van Vuuren A.M. Vroons-de Bruin J., 1995. Rumen degradation and post-ruminal digestion of palm kernel byproducts in dairy cows. Anim. Feed Sci. Technol., 51, 103-121.

Huhtanen P., Sepälä A., Ahvenjärvi S. Rinne M., 2008. Prediction of in vivo neutra detergent fiber digestibility and digestion rate of potential digestible neutral detergent fiber: comparison of models. J. Anim. Sci., 86, 26572669.

INRA, 2007. Alimentation des bovins, ovins et caprins. Besoins des animaux. Valeurs des aliments, Tables INRA 2007. Editions Quae, Paris, France, 307p.
Jarrige R., 1981. Les constituants glucidiques des fourrages : variations, digestibilité et dosage. In : Prévision de la valeur nutritive des aliments des Ruminants. Demarquilly C. (Ed), INRA Publ., Versailles, France, 13-40.

Khorasani G.R., Robinson P.H., Kennelly J.J., 1994. Evaluation of solvent and expeller linseed meals as protein sources for dairy cattle. Can. J. Anim. Sci., 74, 479-485.

Latham M.J., 1980. Adhesion of rumen bacteria to plant cell walls. In: Microbial adhesion to surfaces. Berkeley, R.C.W., Lynch J.M., Melling J., Rutter P.R., Vincent B. (Eds), Ellisharwood Publishers, Chichester, UK, 339-350.

Lindberg J.E., 1981. The effect of basal diet on the ruminal degradation of dry matter, nitrogenous compounds and cell walls in nylon bags. Swedish J. agric. Res., 11, 159-169.

Liu Y.G., Steg A., Hindle V.A., 1994. Rumen degradation and intestinal digestion of crambe and other oilseed by-products in dairy cows. Anim. Feed Sci. Technol., 45, 397-409.

Lopez S., France J., Dhanoa M.S., Mould F., Dijkstra J., 1999. Comparison of mathematical models to describe disappearance curves obtained using the polyester bag technique for incubating feeds in the rumen. J. Anim. Sci., 77, 1875-1888.

Madsen, J., 1985. The basic for the proposed Nordic protein evaluation system for ruminants. Acta Agric. Scand., Suppl. 25, 9-20.

Madsen J., Stensig T., Weisbjerg M.R., Hvelplund T., 1994. Estimation of the physical fill of feedstuffs in the rumen by the in sacco degradation characteristics. Livest. Prod. Sci., 39, 43-47.

McDonald, I., 1981. A revised model for the estimation of protein degradability in the rumen. J. Agric. Sci., 96, 251-252.

McKinnon J.J., Mustafa A.F., Cohen R.D.H., 1995. Nutritional evaluation and processing of canola hulls for ruminants. Can. J. Anim. Sci., $75,231-237$

Mertens D.R., 1973. Application of theoretical mathematical models to cell wall digestion and forage intake in ruminants. Ph.D. Thesis, Cornell University, Ithaca, NY, USA, 217p.

Michalet-Doreau B., Vérité R., Chapoutot P., 1987. Méthodologie de mesure de la dégradabilité in sacco de l'azote des aliments 
dans le rumen. Bull. Tech. CRZV Theix, 69 5-7.

Nocek J.E., Russell J.B., 1988. Protein and energy as an integrated system. Relationship of ruminal protein and carbohydrate availability to microbial synthesis and milk production. J. Dairy Sci., 71, 2070-2107.

Nocek J.E., Tamminga S., 1991. Site of digestion of starch in the gastrointestinal tract of dairy cows and its effect on milk yield and composition. J. Dairy Sci., 74, 3598-3629.

Nozières M.O., Dulphy J.P., Peyraud J.L., Poncet C., Baumont R., 2007. La valeur azotée des fourrages. Nouvelles estimations de la dégradabilité des protéines dans le rumen et de la digestibilité réelle des protéines alimentaires dans l'intestin grêle: conséquences sur les valeurs PDI. INRA Prod. Anim., 20, 109-118.

Offner A., Sauvant D., 2004. Prediction of in vivo starch digestion in cattle from in situ data. Anim. Feed Sci. Technol., 111, 41-56.

Offner A., Bach A., Sauvant D., 2003. Quantitative review of in situ starch degradation in the rumen. Anim. Feed Sci. Technol., 106, 81-93.

Ørskov E.R., McDonald I., 1979. The estimation of protein degradability in the rumen from incubation measurements weighted according to rate of passage. J. Agric. Sci., 92, 499-503.

Peyraud J.L., Apper-Bossard E., 2006 L'acidose latente chez la vache laitière. INRA Prod. Anim., 19, 79-92.

Sauvant D., 1981. Prévision de la valeur énergétique des aliments concentrés et composés pour les ruminants. In: Prévision de la valeur nutritive des aliments des ruminants. Demarquilly C. (Ed). INRA Publ., Versailles, France, 237-258.

Sauvant D., Dorléans M., Delacour C., Bertrand D., Giger, S., 1986a. La modélisation des cinétiques de dégradation des constituants pariétaux des aliments dans le rumen. Reprod. Nutr. Dévelop., 26, 303-304.

Sauvant D., Giger S., Chapoutot P., Dorléans M., 1986b. Variations of the feed cell wall degradation kinetics in the rumen. In: Cell Wall, 10/9/86, Paris, France.

Sauvant D., Chapoutot P., Archimède H., 1994. La digestion des amidons par les ruminants et ses conséquences. INRA Prod. Anim., 7, 115-124.
Sauvant D., Baumont R., Faverdin P., 1996. Development of a mechanistic model of intake and chewing activities of sheep. J. Anim. Sci. 74, 2785-2802.

Sauvant D., Perez J.M., Tran G., 2004 Tables of composition and nutritive value of feed materials: pigs, poultry, cattle, sheep, goats, rabbits, horses, fish. INRA Editions, Paris and Wageningen Academic Publishers, The Netherlands, $304 \mathrm{p}$

Sauvant D., Giger-Reverdin S., Chapoutot P., Archimède H., 2007. Relation entre la digestibilité in vivo du NDF des rations et la dégradabilité in sacco du fourrage qu'elle contient. Renc. Rech. Rum., 246.

Sauvant D., Giger-Reverdin S., Chapouto P., Schmidely P., 2008. Calcul de la digestibilité des parois des aliments concentrés et coproduits par les ruminants. Renc. Rech. Rum., 256.

Sharma B.K., Erdman R.A., Reeves J.B. 1988. Rate and Extent of in situ digestion of medium and high quality alfalfa and orchard grass Neutral Detergent Fiber as determined by extended periods of incubation time. J. Dairy Sci., 71, 3509-3515.

Snedecor G.W., Cochran W.G., 1984 Méthodes statistiques. 6ème édition, Association de Coordination Technique Agricole, Paris, France, 649p.

Sniffen C.J., O'Connor J.D., Van Soest P.J., Fox D.G., Russell J.B., 1992. A net carbohydrate and protein system for evaluating cattle diets: II. Carbohydrate and protein availability. J. Anim. Sci., 70, 3562-3577.

Soofi, R., Fahey, G.C. Jr., Berger, L.L., 1983. Rate and extent of digestion of cotton thread and of dry matter and cell wall constituents of soybean stover, alfalfa and their blends and rumen characteristics of sheep fed these forages. Can. J. Anim. Sci., 63, 373-380

Statistical Analysis Systems Institute Inc. SAS, 2000. SAS/STAT®User's Guide. Release 11.04, SAS Institute Inc., Cary, NC.

Stensig T., Weisbjerg M.R., Madsen J., Hvelplund T., 1994. Estimation of voluntary feed intake from in sacco degradation and rate of passage of NDF. Livest. Prod. Sci., 39, 4952.

Tamburini A., Rapetti L., Crovetto G.M., Susmel P., 1995. Rumen degradability of dry matter, NDF and ADF in Italian ryegrass
(Lolium multiflorum) and winter cereal silages. Zoot. Nutr. Anim. 21, Suppl., 75-80.

Tamminga S., Van Vuuren A.M., Van Der Koelen C.J., Ketelaar R.S., Van der Togt P.L., 1990. Ruminal behaviour of structural carbohydrates, non-structural carbohydrates and crude protein from concentrate ingredients in dairy cows. Neth. J. Agric. Sci., 38, 513-526.

Tedesco D., Pedron O., Giuliani G., Spinola B., 1990. Kinetic of fermentation in the rumen of different forage species. 41 ${ }^{\text {st }}$ Ann. Meet. Eur. Assoc. Anim. Prod., 90, Toulouse, France, 1-3.

Thivend P., 1981. Les constituants glucidiques des aliments concentrés et des sousproduits. In: Prévision de la valeur nutritive des aliments des Ruminants. Demarquilly C. (Ed.), INRA Publ., Versailles, France, 219-235.

Torrent J., Johnson D.E., Kujawa M.A., 1994. Co-product fiber digestibility: kinetic and in vivo assessment. J. Anim. Sci., 72, 790795 .

Van Soest P.J., 1982. Carbohydrates. In: Nutritional ecology of the ruminant. Van Soest P.J. (Ed), O \& B Brooks Inc., Corvallis, USA, 95-117.

Van Soest P.J., Wine R.H., 1967. Use of detergents in the analysis of fibrous feeds. IV. Determination of plant cell wall constituents. J. Assoc. Anal. Chem., 50, 50-55.

Varga G.A., Hoover W.H., 1983. Rate and extent of neutral detergent fiber degradation of feedstuffs in situ. J. Dairy Sci., 60, 2109-2115.

Vérité R., Michalet-Doreau B., Chapoutot P., Peyraud J.L., Poncet C., 1987. Révision du système des Protéines Digestibles dans l'Intestin (PDI). Bull. Tech. CRZV Theix, 70, 19-34.

Vérité R., Michalet-Doreau B., Vedeau F., Chapoutot P., 1990. Dégradabilité en sachets des matières azotées des aliments concentrés: standardisation de la méthode et variabilités intra- et inter laboratoires. Reprod. Nutr. Dev., 30 (Suppl. 2), 161-162.

Yang, W.Z., 1991. Étude cinétique de la colonisation microbienne des aliments dans le rumen du mouton. Conséquences sur la compartimentation de la biomasse et sur sa dynamique de sortie du rumen dans le cas de différents types de rations. Thèse Docteur de l'Université, Université Blaise Pascal, Clermont-Ferrand, France, 391p.

\section{Remerciements}

Les auteurs souhaitent remercier Jean Hervieu, Joseph Tessier, Pierre Poissonnet, Michel Quintard, Antoine Crespin et Jean-Luc Le Pierres pour leur aide technique au cours des essais expérimentaux.

\section{Liste des Abréviations}

NDF neutral detergent fibre, ADF acid detergent fibre, ADL acid detergent lignin, MS matière sèche, MAT matières azotées totales, MM matières minérales, N Azote, CB cellulose brute, DMS disparition de la MS, QNDFd, QADFd, QADLd, quantité de NDF, ADF ou ADL dégradée après incubation dans le rumen, QNDFnd QADFnd QADLnd quantité de NDF, ADF ou ADL non dégradée après incubation dans le rumen, NDFind ADFind ADLind proportion de NDF, ADF ou ADL non dégradable, NDFdeg ADFdeg ADLdeg proportion NDF, ADF ou ADL dégradable, DT, dégradabilité théorique. 


\title{
Résumé
}

Cette étude est la synthèse des mesures de dégradation dans le rumen des constituants pariétaux (NDF, ADF, ADL) par la méthode des sachets de Nylon, appliquées à 217 échantillons représentant environ 80 aliments concentrés et coproduits agroindustriels. Ce jeu de données est l'ensemble le plus complet publié à ce jour en utilisant une méthodologie relativement homogène. Les dynamiques de dégradation des aliments ont été interprétées en utilisant les paramètres de deux modèles d'ajustement non linéaire, le modèle de Mertens (1973) et le modèle d'Ørskov et McDonald (1979) qui prennent en compte (ou non) un temps de latence au démarrage de la dégradation. Ces paramètres montrent de grandes variations intra- et inter-aliments, étroitement reliées à la qualité de la paroi végétale et notamment à l'importance de sa fraction lignifiée dont l'influence diffère fortement d'une famille d'aliments à l'autre. Ce travail a conduit à l'élaboration d'une table cohérente des paramètres de dégradation des constituants pariétaux des aliments concentrés et coproduits qui permettra d'améliorer les systèmes d'unités d'alimentation et pourra être valorisée dans les travaux de modélisation de la digestion dans le rumen.

\begin{abstract}
Study of rumen degradation kinetics of cell wall components of concentrate feeds and agroindustrial by-products

This study was the synthesis of rumen degradation measurements of cell wall components (NDF, ADF, ADL) using the Nylon bag method applied to 217 samples of about 80 concentrate feeds and industrial by-products. This data set is the more complete published collection of results obtained using a homogeneous methodology. The degradation dynamics of the feeds was evaluated using para6meters of two non-linear adjustment models, the Ørskov and McDonald model (1979) and the Mertens model (1973), taking into account (or not) a lag phase at the onset of the degradation. These parameters showed large within- and between-feed variations, closely related to the quality of the cell wall and especially to the importance of its lignified fraction. Moreover, the influence of this criterion strongly differs from a family of food to the other. This work led to the development of a coherent table for degradation parameters of cell wall constituents which will make it possible to improve the feed unit systems for ruminants and could be integra6ted in modelling studies on rumen digestion.
\end{abstract}

CHAPOUTOT P., DORLÉANS M., SAUVANT D., 2010. Etudes des cinétiques de dégradation dans le rumen des constituants pariétaux des aliments concentrés et coproduits agroindustriels. Inra Prod. Anim., 23, 285-304. 
Annexe 1. Composition chimique des aliments.

\section{Annexes}

\begin{tabular}{|c|c|c|c|c|c|c|c|c|c|c|c|c|c|c|}
\hline \multirow{2}{*}{ Famille } & \multirow{2}{*}{ Genre } & \multirow{2}{*}{$\begin{array}{c}\text { (en \% } \\
\text { MS }^{\circ} \text { ) } \\
\text { Nb } \\
\text { échant }\end{array}$} & \multicolumn{2}{|c|}{ MM } & \multicolumn{2}{|c|}{$\mathrm{CB}$} & \multicolumn{2}{|c|}{ MAT } & \multicolumn{2}{|c|}{ NDF } & \multicolumn{2}{|c|}{ ADF } & \multicolumn{2}{|c|}{$A D L$} \\
\hline & & & Moy & $E T$ & Moy & $E T$ & Moy & ET & Moy & $E T$ & Moy & ET & Moy & $E T$ \\
\hline \multirow{3}{*}{ Agrume } & Ecorce & 1 & 6,8 & - & 17,4 & - & 6,1 & - & 26,5 & - & 19,4 & - & 0,5 & - \\
\hline & Ecorce distillée & 1 & 5,9 & - & 22,1 & - & 6,2 & - & 33,7 & - & 24,9 & - & 0,6 & - \\
\hline & Pulpe & 2 & 7,0 & 1,0 & 12,4 & 0,5 & 8,4 & 0,4 & 21,4 & 0,6 & 14,3 & 0,3 & 1,3 & 0,1 \\
\hline \multirow{3}{*}{ Arachide } & Coque & 1 & 8,6 & - & 56,4 & - & 6,7 & - & 72,8 & - & 58,8 & - & 25,0 & - \\
\hline & Coque traitée & 1 & 15,0 & - & 51,7 & - & 6,5 & - & 70,2 & - & 56,4 & - & 23,5 & - \\
\hline & Tourteau & 1 & 7,8 & - & 13,4 & - & 46,4 & - & 19,7 & - & 13,9 & - & 4,3 & - \\
\hline \multirow{2}{*}{ Avoine } & Graine & 2 & 3,5 & 0,1 & 14,1 & 1,2 & 9,1 & 0,1 & 32,6 & 2,0 & 16,9 & 0,4 & 2,9 & 0,4 \\
\hline & Paille & 1 & 7,0 & - & 46,5 & - & 2,8 & - & 80,9 & - & 51,5 & - & 6,5 & - \\
\hline Betterave & Pulpe & 13 & 7,5 & 1,0 & 19,7 & 0,8 & 9,4 & 0,8 & 48,0 & 3,9 & 23,6 & 1,5 & 1,8 & 0,5 \\
\hline & Pulpe enrichie $^{(1)}$ & 12 & 10,1 & 1,1 & 15,9 & 0,5 & 20,1 & 0,8 & 39,6 & 4,2 & 20,0 & 1,0 & 1,7 & 0,7 \\
\hline & Drêche & 3 & 3,2 & 1,8 & 11,8 & 6,0 & 29,0 & 8,4 & 39,9 & 13,0 & 12,9 & 3,0 & 3,7 & 0,7 \\
\hline Blé & Drêche+soluble & 5 & 4,5 & 1,5 & 7,6 & 2,2 & 29,7 & 6,4 & 29,5 & 8,7 & 9,9 & 2,0 & 2,8 & 0,5 \\
\hline & Graine & 6 & 2,0 & 0,1 & 2,8 & 0,4 & 11,6 & 1,0 & 12,7 & 1,3 & 3,5 & 0,3 & 1,1 & 0,2 \\
\hline & Graine tannée & 9 & 1,8 & 0,1 & - & - & 11,0 & 0,5 & 13,5 & 0,9 & 3,6 & 0,4 & 1,1 & 0,1 \\
\hline & Paille & 1 & 6,3 & - & 45,4 & - & 4,0 & - & 85,1 & - & 53,9 & - & 8,3 & - \\
\hline & Soluble & 1 & 2,5 & - & 3,4 & - & 15,5 & - & 11,2 & - & 4,9 & - & 1,3 & - \\
\hline & Son & 2 & 6,9 & 0,4 & 12,3 & 1,6 & 16,9 & 0,4 & 41,5 & 9,8 & 13,5 & 2,3 & 3,6 & 0,8 \\
\hline Carotte & Racine & 1 & 5,5 & - & 8,9 & - & 8,8 & - & 21,8 & - & 13,1 & - & 2,7 & - \\
\hline Chicore & Marc & 1 & 6,8 & - & 21,4 & - & 13,9 & - & 34,6 & - & 29,5 & - & 10,7 & - \\
\hline & Coque & 2 & 9,4 & 4,9 & 20,2 & 3,0 & 16,7 & 1,6 & 61,5 & 18,0 & 45,8 & 16,3 & 24,3 & 8,8 \\
\hline Uiza & Tourteau & 4 & 8,4 & 1,0 & 11,4 & 2,0 & 39,8 & 1,8 & 30,7 & 7,8 & 19,5 & 3,3 & 9,0 & 2,6 \\
\hline & Tourteau dépelliculé & 1 & 8,4 & - & 6,0 & - & 49,1 & - & 14,7 & - & 7,3 & - & 1,5 & - \\
\hline & Tourteau tanne & 1 & 7,7 & - & 13,9 & - & 38,1 & - & 28,8 & - & 19,3 & - & 9,3 & - \\
\hline Coprah & Tourteau & 9 & 7,0 & 1,4 & 16,0 & 3,3 & 22,1 & 2,0 & 55,6 & 9,3 & 29,8 & 5,3 & 10,3 & 8,4 \\
\hline Coton & Graine & 1 & 5,0 & - & 26,0 & - & 22,9 & - & 47,4 & - & 32,4 & - & 9,3 & - \\
\hline & Tourteau & 11 & 7,1 & 0,8 & 14,1 & 3,3 & 44,0 & 4,6 & 31,0 & 10,7 & 19,9 & 5,5 & 6,5 & 2,4 \\
\hline Datte & Noyau & 1 & 1,9 & - & 19,1 & - & 6,3 & - & 69,4 & - & 44,4 & - & 4,5 & - \\
\hline Epinard & Feuilles & 2 & 18,5 & 1,6 & 9,2 & 1,4 & 36,0 & 0,4 & 41,5 & 3,8 & 11,4 & 1,8 & 2,0 & 0,4 \\
\hline Fétuque & Foin & 1 & 7,4 & - & 32,4 & - & 9,1 & - & 65,0 & - & 34,4 & - & 3,4 & - \\
\hline Féverole & Graine & 1 & 4,4 & - & 10,2 & - & 27,8 & - & 21,5 & - & 11,9 & - & 0,2 & - \\
\hline $\begin{array}{l}\text { Haricot } \\
\text { Vert } \\
\end{array}$ & Coproduits & 1 & 15,0 & - & 18,5 & - & 19,3 & - & 31,5 & - & 21,2 & - & 3,7 & - \\
\hline Lin & Tourteau & 2 & 6,3 & 0,3 & 10,4 & 0,7 & 39,0 & 3,8 & 23,3 & 1,4 & 14,7 & 0,1 & 5,6 & 0,3 \\
\hline Lupin & Graine & 2 & 4,3 & 0,2 & 11,9 & 2,1 & 39,9 & 0,2 & 22,3 & 0,2 & 14,2 & 2,1 & 0,7 & 0,0 \\
\hline Luzeme & Déshydratée & 4 & 11,1 & 1,3 & 31,6 & 3,9 & 18,9 & 5,5 & 51,5 & 4,7 & 34,6 & 3,9 & 8,4 & 1,9 \\
\hline & Foin & 2 & 9,7 & 0,1 & 32,0 & 2,1 & 16,8 & 0,6 & 45,9 & 3,0 & 34,7 & 3,5 & 7,7 & 0,2 \\
\hline $\begin{array}{l}\text { Luzeme } \\
\text { + urée }\end{array}$ & Déshydratée & 2 & 12,2 & 3,1 & 25,6 & 1,8 & 48,0 & 1,3 & 39,2 & 2,6 & 28,1 & 2,1 & 6,3 & 0,6 \\
\hline & DDG & 1 & 2,7 & - & 13,9 & - & 37,6 & - & 46,6 & - & 14,7 & - & 2,3 & - \\
\hline Maïs & Drêche & 1 & 0,8 & - & 12,8 & - & 9,9 & - & 52,4 & - & 14,8 & - & 0,9 & - \\
\hline & Ensilage & 2 & 4,7 & 0,3 & 20,0 & 0,4 & 9,7 & 0,1 & 44,4 & 0,8 & 21,7 & 0,4 & 2,0 & 0,1 \\
\hline & Com Gluten Feed & 3 & 5,5 & 0,5 & 8,9 & 0,8 & 20,8 & 1,5 & 39,9 & 2,3 & 10,0 & 0,8 & 0,8 & 0,1 \\
\hline & Com Gluten Meal & 5 & 2,6 & 1,6 & 0,9 & 0,3 & 69,7 & 4,6 & 2,9 & 2,6 & 0,8 & 0,8 & 0,3 & 0,3 \\
\hline & Graine & 7 & 1,5 & 0,1 & 2,7 & 0,5 & 9,3 & 0,8 & 11,8 & 1,2 & 3,0 & 0,3 & 0,4 & 0,1 \\
\hline & Solufactor & 1 & 7,1 & - & 8,4 & - & 29,0 & - & 36,5 & - & 10,3 & - & 1,2 & - \\
\hline & Tourteau de germe & 2 & 3,1 & 0,9 & 12,4 & 2,3 & 22,2 & 4,6 & 43,9 & 9,6 & 12,9 & 1,3 & 1,6 & 1,1 \\
\hline Microorganismes & Levures & 2 & 6,4 & 1,3 & 4,3 & 1,5 & 39,5 & 9,9 & 19,8 & 8,9 & 4,7 & 0,9 & 1,6 & 0,5 \\
\hline Olive & Grignon & 1 & 5,0 & - & 36,7 & - & 8,8 & - & 69,2 & - & 49,5 & - & 20,5 & - \\
\hline Orge & Drêche Brasserie & 2 & 5,0 & 1,3 & 17,5 & 2,3 & 29,1 & 0,5 & 66,1 & 2,8 & 26,0 & 7,9 & 7,6 & 4,0 \\
\hline & Graine & 4 & 2,6 & 0,1 & 5,2 & 0,7 & 15,9 & 5,4 & 18,2 & 2,4 & 5,7 & 0,7 & 0,8 & 0,2 \\
\hline Palmiste & Tourteau & 4 & 4,7 & 1,2 & 20,1 & 4,3 & 18,7 & 4,5 & 70,4 & 5,9 & 39,0 & 4,6 & 11,2 & 4,4 \\
\hline & Tourteau enrichi ${ }^{(2)}$ & 1 & 5,1 & - & 23,3 & - & 16,8 & - & 70,8 & - & 43,2 & - & 14,2 & - \\
\hline & Fanes & 1 & 11,3 & - & 23,4 & - & 14,4 & - & 37,0 & - & 24,7 & - & 3,7 & - \\
\hline Petit pois & Gousses pleines & 1 & 5,2 & - & 12,2 & - & 25,6 & - & 22,6 & - & 13,0 & - & 1,4 & - \\
\hline & Plante entière & 1 & 9,2 & - & 23,2 & - & 24,0 & - & 34,8 & - & 25,0 & - & 3,8 & - \\
\hline & Coproduits & 3 & 12,4 & 5,6 & 16,4 & 3,8 & 22,6 & 0,9 & 27,2 & 8,1 & 17,4 & 4,3 & 2,2 & 0,8 \\
\hline & Tiges + feuilles & 1 & 9,4 & - & 17,9 & - & 25,0 & - & 33,9 & - & 18,3 & - & 2,5 & - \\
\hline Pois & Graine & 2 & 3,5 & 0,2 & 5,7 & 0,1 & 23,8 & 0,8 & 14,7 & 3,1 & 6,4 & 0,4 & 0,2 & 0,0 \\
\hline Pomme & Marc & 1 & 2,3 & - & 16,5 & - & 5,5 & - & 41,7 & - & 30,7 & - & 11,8 & - \\
\hline
\end{tabular}


Annexe 1. (suite)

\begin{tabular}{|c|c|c|c|c|c|c|c|c|c|c|c|c|c|c|}
\hline \multirow{2}{*}{ Alim } & \multirow{2}{*}{ Genre } & \multirow{2}{*}{$\begin{array}{c}\text { (en \% } \\
\text { MS) }\end{array}$} & \multicolumn{2}{|c|}{ MM } & \multicolumn{2}{|c|}{$\mathrm{CB}$} & \multicolumn{2}{|c|}{ MAT } & \multicolumn{2}{|c|}{ NDF } & \multicolumn{2}{|c|}{ ADF } & \multicolumn{2}{|c|}{$A D L$} \\
\hline & & & Moy & $E T$ & Moy & $E T$ & Moy & $E T$ & Moy & $E T$ & Moy & $E T$ & Moy & $E T$ \\
\hline \multirow{5}{*}{ Pomme de terre } & Ensilage & 1 & 3,1 & - & 6,1 & - & 7,5 & - & 9,8 & - & 6,5 & - & 1,5 & - \\
\hline & Pelures & 1 & 2,8 & - & 5,9 & - & 7,1 & - & 11,1 & - & 8,1 & - & 1,7 & - \\
\hline & Pelures vapeur & 1 & 7,0 & - & 22,0 & - & 14,4 & - & 66,5 & - & 46,2 & - & 26,8 & - \\
\hline & Purée & 1 & 3,7 & - & 3,4 & - & 10,1 & - & 8,0 & - & 5,3 & - & 1,0 & - \\
\hline & Racine & 2 & 4,9 & 0,4 & 2,5 & 0,2 & 10,2 & 1,1 & 4,9 & 0,3 & 3,2 & 0,1 & 0,6 & 0,1 \\
\hline \multirow{4}{*}{ Raisin } & Marc & 1 & 4,5 & - & 30,3 & - & 12,3 & - & 68,6 & - & 60,8 & - & 42,2 & - \\
\hline & Pépin & 4 & 3,6 & 0,5 & 35,8 & 1,3 & 9,6 & 0,9 & 74,4 & 1,5 & 64,6 & 1,9 & 50,7 & 2,8 \\
\hline & Pulpe & 7 & 7,6 & 1,7 & 25,1 & 1,9 & 14,5 & 0,6 & 66,7 & 2,9 & 58,7 & 3,2 & 38,3 & 3,8 \\
\hline & Pulpe enrichie ${ }^{(3)}$ & 1 & 7,4 & - & 21,1 & - & 14,9 & - & 60,0 & - & 53,0 & - & 35,0 & - \\
\hline Salsifis & Racine & 1 & 13,8 & - & 6,9 & - & 11,8 & - & 14,1 & - & 10,4 & - & 3,0 & - \\
\hline \multirow{3}{*}{ Soja } & Coque & 4 & 5,1 & 0,2 & 37,0 & 0,9 & 14,4 & 1,5 & 62,7 & 2,7 & 43,4 & 1,2 & 1,5 & 0,4 \\
\hline & Tourteau & 4 & 7,1 & 0,2 & 5,1 & 1,3 & 53,2 & 1,7 & 9,7 & 2,6 & 5,7 & 1,5 & 0,3 & 0,1 \\
\hline & Tourteau tanné & 2 & 7,2 & 0,1 & 5,5 & 1,8 & 52,3 & 2,2 & 10,3 & 3,6 & 5,9 & 1,6 & 0,4 & 0,1 \\
\hline Soja/colza & Graine extrudée & 1 & 7,1 & - & 9,2 & - & 45,6 & - & 19,4 & - & 12,1 & - & 3,6 & - \\
\hline \multirow[t]{2}{*}{ Sorgho } & DDG & 1 & 2,3 & - & 10,8 & - & 35,6 & - & 70,2 & - & 40,9 & - & 19,5 & - \\
\hline & Graine & 1 & 1,8 & - & 2,0 & - & 10,2 & - & 7,9 & - & 3,3 & - & 0,8 & - \\
\hline Tomate & Pulpe & 5 & 4,0 & 0,4 & 41,0 & 0,8 & 18,9 & 1,1 & 56,9 & 1,4 & 44,2 & 1,2 & 24,3 & 2,0 \\
\hline Topinambour & Racine & 1 & 5,8 & - & 4,0 & - & 8,1 & - & 9,5 & - & 6,0 & - & 1,2 & - \\
\hline \multirow{3}{*}{ Toumesol } & Coque & 2 & 3,7 & 0,0 & 55,8 & 5,0 & 6,2 & 2,1 & 80,7 & 4,5 & 61,9 & 3,7 & 22,2 & 1,8 \\
\hline & Coque + amande & 1 & 3,1 & - & 35,4 & - & 10,6 & - & 46,5 & - & 35,0 & - & 12,9 & - \\
\hline & Tourteau & 1 & 7,6 & - & 25,1 & - & 32,4 & - & 40,9 & - & 28,0 & - & 9,1 & - \\
\hline
\end{tabular}

(1) Pulpe de betterave enrichie en mélasse + vinasses.

(2) Tourteau de palmiste enrichi en mélasse.

(3) Pulpe de raisin enrichie en jus de raisin. 
Annexe 2. Paramètres de dégradation du NDF des aliments concentrés et coproduits.

\begin{tabular}{|c|c|c|c|c|c|c|c|c|c|c|c|c|c|c|c|c|c|}
\hline \multirow[t]{2}{*}{ Famille } & \multirow[t]{2}{*}{ Genre } & \multirow[t]{2}{*}{ Nbéch } & \multirow{2}{*}{$\begin{array}{c}\text { ETR } \\
(\% \mathrm{MS})\end{array}$} & \multicolumn{2}{|c|}{$\begin{array}{c}\text { NDF } \\
(\% \mathrm{MS})\end{array}$} & \multicolumn{2}{|c|}{$\begin{array}{l}\text { QNDFnd } \\
\text { (\% MS) }\end{array}$} & \multicolumn{2}{|c|}{$\begin{array}{l}\text { QNDFd } \\
(\% \mathrm{MS})\end{array}$} & \multicolumn{2}{|c|}{$\begin{array}{c}\mathrm{c}_{\circledast} \mathrm{NDF} \\
\left(\mathrm{h}^{-1}\right)\end{array}$} & \multicolumn{2}{|c|}{$\begin{array}{c}c_{M} N D F \\
\left(h^{-1}\right)\end{array}$} & \multicolumn{2}{|c|}{$\begin{array}{c}\mathrm{d}_{M} \mathrm{NDF} \\
\left(\mathrm{h}^{-1}\right)\end{array}$} & \multicolumn{2}{|c|}{$\begin{array}{l}\text { DTNDF } \\
\text { (\%NDF) }\end{array}$} \\
\hline & & & & Moy & $E T$ & Moy & $E T$ & Moy & $E T$ & Moy & $E T$ & Moy & $E T$ & Moy & $E T$ & Moy & $E T$ \\
\hline \multirow[t]{4}{*}{ Agrume } & Ecorce & 1 & 1,0 & 26.5 & - & 2.1 & - & 24,4 & - & & & 0,171 & - & 0,059 & - & 51,8 & - \\
\hline & $\begin{array}{l}\text { Ecorce } \\
\text { distillée }\end{array}$ & 1 & 0.6 & 33,7 & - & 1,8 & - & 31,9 & - & & & 0,097 & - & 0,097 & - & 48.6 & - \\
\hline & \multirow[t]{2}{*}{ Pulpe } & 1 & 3,2 & 21,8 & - & 1,2 & - & 20,6 & - & 0,108 & - & & & & & 60,8 & - \\
\hline & & 1 & 0.7 & 21,0 & - & 2.5 & - & 18.5 & - & & & 0,251 & - & 0,035 & - & 49.6 & - \\
\hline Arachide & Coque & 1 & 0.4 & 72,8 & - & 62.9 & - & 9,9 & - & 0,330 & - & & & & & 11.5 & - \\
\hline & $\begin{array}{l}\text { Coque } \\
\text { traitée }\end{array}$ & 1 & 1.0 & 70,2 & - & 60,0 & - & 10.2 & - & 0.218 & - & & & & & 11,4 & - \\
\hline & Tourteau & 1 & 0,6 & 19,7 & - & 11,3 & - & 8,4 & - & 0.139 & - & & & & & 29.9 & - \\
\hline Avoine & Graine & 2 & 0,9 & 32,6 & 2,0 & 21,2 & 4,3 & 11.4 & 6,2 & 0,082 & 0,083 & & & & & 14,3 & 2,0 \\
\hline & Paille & 1 & 5,3 & 80,9 & - & 26.2 & - & 54,7 & - & 0,027 & - & & & & & 21,0 & - \\
\hline Betterave & Pulpe & 2 & 1.9 & 49,0 & 3,2 & 4.9 & 2,3 & 44.0 & 5,4 & 0,116 & 0,025 & & & & & 59,0 & 7,9 \\
\hline & & 11 & 1.4 & 47.8 & 4,1 & 4.8 & 1,7 & 42,9 & 4,5 & & & 0,285 & 0,170 & 0.076 & 0,054 & 54.7 & 6,5 \\
\hline & $\begin{array}{l}\text { Pulpe } \\
\text { Enrichie }^{(1)}\end{array}$ & 12 & 0.8 & 39,6 & 4,2 & 3.8 & 0,7 & 35,8 & 4,0 & & & 0,211 & 0,112 & 0,119 & 0,047 & 57.8 & 5,8 \\
\hline Blé & Drêche & 3 & 2,3 & 39.9 & 13,0 & 14.8 & 1,5 & 25.1 & 12,1 & 0,129 & 0,082 & & & & & 37,4 & 6,6 \\
\hline & $\begin{array}{l}\text { Drêche } \\
+ \text { +Soluble }\end{array}$ & 5 & 0.6 & 29,5 & 8,7 & 10.9 & 3,6 & 18.7 & 6,2 & 0,127 & 0,054 & & & & & 41,9 & 10,0 \\
\hline & Graine & 6 & 0,6 & 12,7 & 1,3 & 3,0 & 1,8 & 9.7 & 1,2 & 0,050 & 0,019 & & & & & 32.7 & 3,0 \\
\hline & $\begin{array}{l}\text { Graine } \\
\text { tannée }\end{array}$ & 9 & 0,5 & 13,5 & 0,9 & 4,2 & 0,6 & 9,3 & 0,9 & 0.075 & 0,025 & & & & & 36.9 & 4,7 \\
\hline & Paille & 1 & 3,4 & 85,1 & - & 52,5 & - & 32,6 & - & & & 0,035 & - & 0,071 & - & 11,0 & - \\
\hline & Soluble & 1 & 0,3 & 11.2 & - & 5,9 & - & 5,3 & - & 0,063 & - & & & & & 24,2 & - \\
\hline & Son & 2 & 1,3 & 41,5 & 9,8 & 23,6 & 5,0 & 17.9 & 4,9 & 0.104 & 0,037 & & & & & 26.9 & 4,6 \\
\hline Carotte & Racine & 1 & 1,2 & 21,8 & - & 3,6 & - & 18,2 & - & & & 0,344 & - & 0,034 & - & 50,7 & - \\
\hline Chicore & Marc & 1 & 1,8 & 34,6 & - & 4,9 & - & 29,7 & - & & & 0,606 & - & 0,011 & - & 46,4 & - \\
\hline Colza & Coque & 1 & 1.6 & 48,8 & - & 32.7 & - & 16.1 & - & 0.071 & - & & 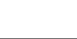 & & 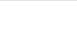 & 17.9 & - \\
\hline & & 1 & 0.7 & 74,2 & - & 50,6 & - & 23,6 & - & & & 0,219 & - & 0,036 & - & 17,3 & - \\
\hline & Tourteau & 3 & 1,0 & 31.9 & 9,1 & 13.3 & 3,2 & 18.5 & 7,7 & 0,056 & 0,007 & & & & & 27.4 & 5,7 \\
\hline & & 1 & 1,2 & 27,3 & - & 10.4 & - & 16.9 & - & & & 0,094 & - & 0,141 & - & 33,3 & - \\
\hline & $\begin{array}{l}\text { Tourteau } \\
\text { dépelliculé }\end{array}$ & 1 & 0,2 & 14,7 & - & 3,7 & - & 11,0 & - & & & 0,096 & - & 0.175 & - & 41,7 & - \\
\hline & $\begin{array}{l}\text { Tourteau } \\
\text { tanné }\end{array}$ & 1 & 0,5 & 28,8 & - & 12,9 & - & 15,9 & - & & & 0,036 & - & 0,072 & - & 16.2 & - \\
\hline Coprah & Tourteau & 9 & 1,3 & 55,6 & 9,3 & 10,8 & 4,8 & 44,8 & 6,7 & & & 0,224 & 0,114 & 0,035 & 0,021 & 39,1 & 5,2 \\
\hline Coton & Graine & 1 & 1,3 & 47.4 & - & 34,7 & - & 12.7 & - & & & 0,037 & - & 0,061 & - & 7.6 & - \\
\hline & Tourteau & 2 & 1,3 & 19.7 & 4,9 & 7,3 & 7,7 & 12,4 & 2,8 & 0,072 & 0,011 & & & & & 37.0 & 19,3 \\
\hline & & 9 & 1.1 & 33,5 & 10,0 & 10,5 & 4,0 & 23,0 & 6,8 & & & 0,091 & 0,036 & 0,094 & 0,090 & 30,0 & 4,1 \\
\hline Datte & Noyau & 1 & 5,2 & 69,4 & - & 4,5 & - & 64,9 & - & & & 0,047 & - & 0,035 & - & 25,4 & - \\
\hline Epinard & Feuilles & 2 & 1,2 & 41,5 & 3,8 & 2.3 & 0,2 & 39,2 & 4,0 & & & 0,293 & 0,169 & 0,034 & 0,024 & 51,7 & 0,6 \\
\hline Fétuque & Foin & 1 & 2.7 & 65,0 & - & 18.8 & - & 46.2 & - & & & 0,041 & - & 0.115 & - & 24,9 & - \\
\hline Féverole & Graine & 1 & 0,5 & 21,5 & - & 2,6 & - & 18,9 & - & 0,077 & - & & & & & 49,4 & - \\
\hline Haricot Vert & Coproduits & 1 & 3.7 & 31,5 & - & 8.2 & - & 23,3 & - & & & 0,178 & - & 0,035 & - & 37,4 & - \\
\hline Lin & Tourteau & 2 & 0.6 & 23,3 & 1,4 & 9,2 & 7,5 & 14.1 & 8,9 & 0,032 & 0,021 & & & & & 16,9 & 2,4 \\
\hline Lupin & Graine & 2 & 1,7 & 22,3 & 0,2 & 2.1 & 1,0 & 20.1 & 0,7 & 0,084 & 0,016 & & & & & 52,3 & 1,9 \\
\hline Luzerne & Déshydratée & 1 & 1,9 & 57.8 & - & 28,3 & - & 29.5 & - & 0.057 & - & & & & & 24,8 & - \\
\hline & & 3 & 0,9 & 49,3 & 2,4 & 21,6 & 4,1 & 27,8 & 2,3 & & & 0,111 & 0,045 & 0,106 & 0,047 & 29,3 & 4,1 \\
\hline & Foin & 1 & 0,4 & 48,0 & - & 25,7 & - & 22,3 & - & 0.123 & - & & & & & 31,2 & - \\
\hline & & 1 & 0,5 & 43.7 & - & 26.2 & - & 17.5 & - & & & 0,154 & - & 0,189 & - & 26.2 & - \\
\hline Luzerne+Urée & Déshydratée & 2 & 0.7 & 39,2 & 2,6 & 18,6 & 1,1 & 20,6 & 1,5 & 0,099 & 0,027 & & & & & 32,4 & 3,2 \\
\hline Maĩs & DDG & 1 & 0,9 & 46,6 & - & 4,6 & - & 42,0 & - & & & 0,055 & - & 0,023 & - & 22,6 & - \\
\hline & Drêche & 1 & 1,4 & 52,4 & - & 5,8 & - & 46,6 & - & & & 0,058 & - & 0,018 & - & 20,6 & - \\
\hline & Ensilage & 2 & 2,2 & 44,4 & 0,8 & 16.8 & 0,1 & 27.6 & 0,7 & 0,061 & 0,002 & & & & & 31,2 & 0,8 \\
\hline & $\begin{array}{l}\text { Com Gluten } \\
\text { Feed }\end{array}$ & 3 & 1,8 & 39.9 & 2,3 & 4,8 & 2,4 & 35.1 & 0,3 & 0,046 & 0,007 & & & & & 37.9 & 1,7 \\
\hline & $\begin{array}{l}\text { Com Gluten } \\
\text { Meal }\end{array}$ & 4 & 0.9 & 3,5 & 2,6 & $-0,2$ & 0,8 & 3.7 & 2,9 & 0,037 & 0,013 & & & & & 36.5 & 5,2 \\
\hline & & 1 & 0,3 & 0,8 & - & 0.1 & - & 0,7 & - & & & 0,044 & - & 0,049 & - & 27.5 & - \\
\hline & Graine & 7 & 0,9 & 11,8 & 1,2 & $-3,5$ & 1,9 & 15,4 & 2,5 & 0,018 & 0,003 & & & & & 29,5 & 1,5 \\
\hline & Solufactor & 1 & 1,0 & 36,5 & - & 5.5 & - & 31,0 & - & & & 0,298 & - & 0,011 & - & 36,0 & - \\
\hline & $\begin{array}{l}\text { Tourteau } \\
\text { de germe }\end{array}$ & 2 & 2,6 & 43,9 & 9,6 & 5,1 & 3,3 & 38,8 & 6,4 & & & 0,070 & 0,026 & 0,093 & 0,074 & 35,8 & 1,2 \\
\hline Microorganismes & Levures & 2 & 0,7 & 19,8 & 8,9 & 3,1 & 1,4 & 16.7 & 10,3 & 0,123 & 0,058 & & & & & 53,7 & 19,2 \\
\hline
\end{tabular}


Annexe 2. (suite)

\begin{tabular}{|c|c|c|c|c|c|c|c|c|c|c|c|c|c|c|c|c|c|}
\hline \multirow[t]{2}{*}{ Famille } & \multirow[t]{2}{*}{ Genre } & \multirow[t]{2}{*}{ Nbéch } & \multirow{2}{*}{$\begin{array}{c}\text { ETR } \\
(\% \mathrm{MS})\end{array}$} & \multicolumn{2}{|c|}{$\begin{array}{c}\text { NDF } \\
(\% \mathrm{MS})\end{array}$} & \multicolumn{2}{|c|}{$\begin{array}{l}\text { QNDFnd } \\
\text { (\% MS) }\end{array}$} & \multicolumn{2}{|c|}{$\begin{array}{l}\text { QNDFd } \\
(\% \mathrm{MS})\end{array}$} & \multicolumn{2}{|c|}{$\begin{array}{c}c_{\wp} N D F \\
\left(h^{-1}\right)\end{array}$} & \multicolumn{2}{|c|}{$\begin{array}{c}\left.C_{M N D F} N-1\right) \\
\left(h^{-1}\right)\end{array}$} & \multicolumn{2}{|c|}{$\begin{array}{c}d_{M} N D F \\
\left(h^{-1}\right)\end{array}$} & \multicolumn{2}{|c|}{$\begin{array}{l}\text { DTNDF } \\
\text { (\%NDF) }\end{array}$} \\
\hline & & & & Moy & $E T$ & Moy & $E T$ & Moy & $E T$ & Moy & $E T$ & Moy & $E T$ & Moy & $E T$ & Moy & $E T$ \\
\hline Olive & Grignon & 1 & 1.8 & 69,2 & - & 49,9 & - & 19,3 & - & 0.176 & - & & & & & 20.8 & - \\
\hline \multirow[t]{3}{*}{ Orge } & \multirow[t]{2}{*}{$\begin{array}{l}\text { Drêche } \\
\text { Brasserie }\end{array}$} & 1 & 2,3 & 64,1 & - & 13.9 & - & 50,2 & - & 0,030 & - & & & & & 26.1 & - \\
\hline & & 1 & 2.2 & 68.1 & - & 28,5 & - & 39,6 & - & & & 0,163 & - & 0,010 & - & 18,2 & - \\
\hline & Graine & 4 & 1.4 & 18,2 & 2,4 & 8.1 & 1,5 & 10,1 & 3,2 & 0,076 & 0,029 & & & & & 29,1 & 8,6 \\
\hline \multirow[t]{2}{*}{ Palmiste } & Tourteau & 4 & 1.8 & 70,4 & 5,9 & 17.1 & 8,9 & 53,3 & 9,0 & & & 0,155 & 0,104 & 0,066 & 0,070 & 33,8 & 6,6 \\
\hline & $\begin{array}{l}\text { Tourteau } \\
\text { enrichi }^{(2)}\end{array}$ & 1 & 5.9 & 70.8 & - & $-20,5$ & - & 91,3 & - & 0,012 & - & & & & & 21,5 & - \\
\hline \multirow[t]{5}{*}{ Petit Pois } & Fanes & 1 & 1.8 & 37,0 & - & 16.7 & - & 20,3 & - & 0,087 & - & & & & & 32,5 & - \\
\hline & $\begin{array}{l}\text { Gousses } \\
\text { pleines }\end{array}$ & 1 & 1.8 & 22,6 & - & 2,2 & - & 20,4 & - & & & 0.110 & - & 0.105 & - & 49,2 & - \\
\hline & $\begin{array}{l}\text { Plante } \\
\text { entière }\end{array}$ & 1 & 1.8 & 34,8 & - & 15,7 & - & 19,1 & - & & & 0,222 & - & 0,033 & - & 29,3 & - \\
\hline & Coproduits & 3 & 1,1 & 27,2 & 8,1 & 3,5 & 3,0 & 23,7 & 8,7 & & & 0.144 & 0,051 & 0,072 & 0,047 & 45,6 & 5,9 \\
\hline & $\begin{array}{l}\text { Tiges } \\
+ \text { Feuilles } \\
\end{array}$ & 1 & 0.4 & 33.9 & - & 10,0 & - & 23.9 & - & & & 0,149 & - & 0.473 & - & 48.8 & - \\
\hline \multirow[t]{2}{*}{ Pois } & \multirow[t]{2}{*}{ Graine } & 1 & 1.5 & 12,5 & - & $-2,7$ & - & 15,2 & - & 0,034 & - & & & & & 44,1 & - \\
\hline & & 1 & 0.8 & 16.9 & - & 1,3 & - & 15,6 & - & & & 0,147 & - & 0,089 & - & 53,8 & - \\
\hline Pomme & Marc & 1 & 0.7 & 41.7 & - & 9.1 & - & 32,6 & - & 0.051 & - & & & & & 35,9 & - \\
\hline \multirow[t]{5}{*}{$\begin{array}{l}\text { Pomme } \\
\text { de terre }\end{array}$} & Ensilage & 1 & 0.8 & 9.8 & - & 1,0 & - & 8.8 & - & 0,071 & - & & & & & 48,5 & - \\
\hline & Pelures & 1 & 0.5 & 11,1 & - & 3,0 & - & 8.1 & - & 0,061 & - & & & & & 36,9 & - \\
\hline & $\begin{array}{l}\text { Pelures } \\
\text { vapeur }\end{array}$ & 1 & 0.8 & 66,5 & - & 49,6 & - & 16.9 & - & & & 0,161 & - & 0,156 & - & 16.4 & - \\
\hline & Purée & 1 & 0.6 & 8,0 & - & 0,4 & - & 7.6 & - & & & 0,053 & - & 0,096 & - & 37,0 & - \\
\hline & Racine & 2 & 0,5 & 4,9 & 0,3 & 1,5 & 0,1 & 3,4 & 0,4 & 0,089 & 0,047 & & & & & 39,2 & 6,9 \\
\hline \multirow[t]{5}{*}{ Raisin } & Marc & 1 & 1.1 & 68,6 & - & 49,4 & - & 19,2 & - & 0,103 & - & & & & & 17.7 & - \\
\hline & Pépin & 4 & 1.1 & 74.4 & 1,5 & 59,8 & 2,4 & 14,6 & 1,2 & 0,141 & 0,022 & & & & & 13,7 & 1,3 \\
\hline & Pulpe & 6 & 0.8 & 67,4 & 2,5 & 42,9 & 5,3 & 24,4 & 4,2 & 0,059 & 0,006 & & & & & 18.0 & 3,2 \\
\hline & & 1 & 0.1 & 62,7 & - & 39,7 & - & 23,0 & - & & & 0,065 & - & 0,102 & - & 16,0 & - \\
\hline & $\begin{array}{l}\text { Pulpe } \\
\text { Ennichie }{ }^{(3)}\end{array}$ & 1 & 1.4 & 60,0 & - & 33.6 & - & 26.4 & - & 0,118 & - & & & & & 29,1 & - \\
\hline Salsifis & Racine & 1 & 0.9 & 14.1 & - & 3.9 & - & 10,2 & - & 0,192 & - & & & & & 55,1 & - \\
\hline Soja & Coque & 1 & 4.5 & 62,5 & - & 14.5 & - & 48,0 & - & 0,081 & - & & & & & 44.1 & - \\
\hline & & 3 & 3,6 & 62,7 & 3,3 & 6.8 & 5,6 & 55,9 & 3,2 & & & 0,076 & 0,021 & 0,081 & 0,041 & 38,4 & 4,8 \\
\hline & Tourteau & 2 & 0.9 & 7.9 & 0,8 & $-1,1$ & 2,3 & 9,0 & 3,1 & 0,044 & 0,028 & & & & & 42,9 & 7,2 \\
\hline & & 2 & 0.7 & 11,6 & 2,3 & 0.2 & 0,7 & 11,3 & 3,0 & & & 0,095 & 0,052 & 0,025 & 0,013 & 31,4 & 0,6 \\
\hline & $\begin{array}{l}\text { Tourteau } \\
\text { tanné }\end{array}$ & 1 & 0.6 & 7.7 & - & $-0,2$ & - & 7.9 & - & 0,029 & - & & & & & 33,3 & - \\
\hline & & 1 & 0.9 & 12,8 & - & 0.3 & - & 12,5 & - & & & 0.122 & - & 0,009 & - & 24,7 & - \\
\hline Soja/Colza & $\begin{array}{l}\text { Graine } \\
\text { extrudée }\end{array}$ & 1 & 0.8 & 19,4 & - & 3,4 & - & 16.0 & - & & & 0.112 & - & 0,014 & - & 24,8 & - \\
\hline Sorgho & DDG & 1 & 3,1 & 70,2 & - & 39,4 & - & 30,8 & - & 0,037 & - & & & & & 16,7 & - \\
\hline & Graine & 1 & 0.1 & 7.9 & - & 3,1 & - & 4.8 & - & & & 0,120 & - & 0,032 & - & 25,8 & - \\
\hline Tomate & Pulpe & 1 & 2.6 & 54,8 & - & 27.9 & - & 26.9 & - & 0,093 & - & & & & & 29,9 & - \\
\hline & & 4 & 0.5 & 57,4 & 0,9 & 30,2 & 2,9 & 27.2 & 2,0 & & & 0,366 & 0,069 & 0,048 & 0,021 & 30,6 & 2,1 \\
\hline Topinambour & Racine & 1 & 2,4 & 9,5 & - & 2,6 & - & 6.9 & - & 0,248 & - & & & & & 58.1 & - \\
\hline Tournesol & Coque & 1 & 1,3 & 77.5 & - & 63.5 & - & 14,0 & - & 0.122 & - & & & & & 12,1 & - \\
\hline & & 1 & 0,0 & 83.8 & - & 69.7 & - & 14,1 & - & & & 0,168 & - & 0,201 & - & 11,3 & - \\
\hline & $\begin{array}{l}\text { Coque } \\
+ \text { Amande }\end{array}$ & 1 & 0.8 & 46.5 & - & 35.8 & - & 10,7 & - & 0,090 & - & & & & & 13,7 & - \\
\hline & Tourteau & 1 & 0,6 & 40,9 & - & 26.5 & - & 14,4 & - & & & 0,109 & - & 0,142 & - & 20,0 & - \\
\hline
\end{tabular}

(1) Pulpe de betterave enrichie en mélasse + vinasses.

(2) Tourteau de palmiste enrichi en mélasse.

(3) Pulpe de raisin enrichie en jus de raisin.

Moyennes (Moy) et écarts types (ET) calculés sur les échantillons les mieux ajustés individuellement par le modèle d'Ørskov et McDonald (1979) (Ø) ou le modèle de Mertens (1973) (M).

Pour des raisons de lisibilité, les tableaux ne présentent que les données relatives aux matières premières (en gris: modèle $\varnothing$, en blanc: modèle $\mathrm{M}$ ). 
Annexe 3. Paramètres de dégradation de l'ADF.

\begin{tabular}{|c|c|c|c|c|c|c|c|c|c|c|c|c|c|c|c|c|c|}
\hline \multirow{2}{*}{ Famille } & \multirow{2}{*}{ Genre } & \multirow{2}{*}{$\begin{array}{l}\mathrm{Nb} \\
\text { éch }\end{array}$} & \multirow{2}{*}{$\begin{array}{c}\text { ETR } \\
\text { (\%MS) }\end{array}$} & \multicolumn{2}{|c|}{$\begin{array}{c}\text { ADF } \\
(\% \mathrm{MS})\end{array}$} & \multicolumn{2}{|c|}{$\begin{array}{l}\text { QADFnd } \\
(\% \mathrm{MS})\end{array}$} & \multicolumn{2}{|c|}{$\begin{array}{l}\text { QADFd } \\
\text { (\% MS) }\end{array}$} & \multicolumn{2}{|c|}{$\begin{array}{c}C_{g} A D F \\
\left(h^{-1}\right)\end{array}$} & \multicolumn{2}{|c|}{$\begin{array}{c}C_{M} \text { ADF } \\
\left(h^{-1}\right)\end{array}$} & \multicolumn{2}{|c|}{$\begin{array}{c}d_{M A D F} A D \\
\left(h^{-1}\right)\end{array}$} & \multicolumn{2}{|c|}{$\begin{array}{l}\text { DTADF } \\
\text { (\% ADF) }\end{array}$} \\
\hline & & & & Moy & $E T$ & Moy & $E T$ & Moy & $E T$ & Moy & $E T$ & Moy & $E T$ & Moy & $E T$ & Moy & $E T$ \\
\hline Agnume & Ecorce & 1 & 0,6 & 19,4 & - & 1.6 & - & 17.8 & - & & & 0,180 & - & 0,042 & - & 48.7 & - \\
\hline & $\begin{array}{l}\text { Ecorce } \\
\text { distillée }\end{array}$ & 1 & 0,0 & 24,9 & - & 1,0 & - & 23.9 & - & & & 0,083 & - & 0,151 & - & 49,6 & - \\
\hline & Pulpe & 2 & 1.7 & 14,3 & 0,3 & 0,3 & 0,3 & 14,0 & 0,1 & 0,088 & 0,025 & & & & & 57,5 & 5,4 \\
\hline Arachide & Coque & 1 & 0,8 & 58,8 & - & 51.7 & - & 7.1 & - & 0,332 & - & & & & & 10,2 & - \\
\hline & $\begin{array}{l}\text { Coque } \\
\text { traitée }\end{array}$ & 1 & 1,2 & 56.4 & - & 49,7 & - & 6.7 & - & 0,493 & - & & & & & 10,7 & - \\
\hline & Tourteau & 1 & 0.1 & 13,9 & - & 8.9 & - & 5.0 & - & & & 0,273 & - & 0,154 & - & 26,3 & - \\
\hline Avoine & Graine & 2 & 0.7 & 16,9 & 0,4 & 6.7 & 10,3 & 10,1 & 10,7 & 0,035 & 0,035 & & & & & 11,2 & 5,0 \\
\hline & Paille & 1 & 3.6 & 51,5 & - & 14,9 & - & 36.6 & - & 0,025 & - & & & & & 20,9 & - \\
\hline Betterave & Pulpe & 2 & 1.2 & 22,6 & 0,1 & 3,4 & 0,8 & 19,2 & 0,9 & 0,113 & 0,049 & & & & & 54.5 & 11,0 \\
\hline & & 11 & 0,7 & 23,8 & 1,6 & 3,2 & 1,4 & 20,6 & 1,0 & & & 0,329 & 0,169 & 0,065 & 0,060 & 51.7 & 7,7 \\
\hline & $\begin{array}{l}\text { Pulpe } \\
\text { enrichie }\end{array}$ & 4 & 1,4 & 19,4 & 0,7 & 1,3 & 0,1 & 18,1 & 0,7 & 0.119 & 0,024 & & & & & 61,5 & 4,1 \\
\hline & & 8 & 0.4 & 20,3 & 1,0 & 2.4 & 0,5 & 17.9 & 1,1 & & & 0,395 & 0,261 & 0,073 & 0,046 & 56.4 & 7,1 \\
\hline Blé & Drêche & 3 & 0,5 & 12,9 & 3,0 & 8.5 & 1,7 & 4,5 & 1,6 & 0,089 & 0,013 & & & & & 20,3 & 2,9 \\
\hline & $\begin{array}{l}\text { Drêche } \\
+ \text { soluble }\end{array}$ & 5 & 0,3 & 9.9 & 2,0 & 5.4 & 2,0 & 4,5 & 1,6 & 0.157 & 0,154 & & & & & 31.4 & 19,9 \\
\hline & Graine & 6 & 0.2 & 3.5 & 0,3 & 1,3 & 0,6 & 2,2 & 0,7 & 0,037 & 0,025 & & & & & 19,7 & 5,5 \\
\hline & $\begin{array}{l}\text { Graine } \\
\text { tannée }\end{array}$ & 9 & 0,2 & 3,6 & 0,4 & 0,3 & 1,3 & 3,2 & 1,5 & 0,016 & 0,006 & & & & & 16.6 & 1,3 \\
\hline & Paille & 1 & 2,0 & 53,9 & - & 36.9 & - & 17,0 & - & & & 0,060 & - & 0,049 & - & 11.0 & - \\
\hline & Soluble & 1 & 0,2 & 4,9 & - & 3,1 & - & 1,8 & - & 0,063 & - & & & & & 18,8 & - \\
\hline & Son & 2 & 0.2 & 13,5 & 2,3 & 9.8 & 1,6 & 3.7 & 0,6 & 0,054 & 0,025 & & & & & 12.7 & 3,3 \\
\hline Carotte & Racine & 1 & 0.2 & 13,1 & - & 2.1 & - & 11.0 & - & & & 0.282 & - & 0,029 & - & 46.8 & - \\
\hline Chicore & Marc & 1 & 2.2 & 29,5 & - & 2,4 & - & 27.1 & - & & & 0,162 & - & 0,047 & - & 48,3 & - \\
\hline Colza & Coque & 2 & 1.1 & 45,8 & 16,3 & 37,4 & 12,6 & 8.3 & 3,8 & 0,084 & 0,052 & & & & & 9.7 & 1,9 \\
\hline & Tourteau & 3 & 0.9 & 17.9 & 1,3 & 9,6 & 3,7 & 8.3 & 4,5 & 0.102 & 0,071 & & & & & 23.8 & 15,1 \\
\hline & & 1 & 0,5 & 24,1 & - & 14,7 & - & 9.4 & - & & & 0.101 & - & 0,077 & - & 19,4 & - \\
\hline & $\begin{array}{l}\text { Tourteau } \\
\text { dépelliculé }\end{array}$ & 1 & 0.5 & 7,3 & - & 3,3 & - & 4,0 & - & 0,098 & - & & & & & 34,2 & - \\
\hline & $\begin{array}{l}\text { Tourteau } \\
\text { tanné }\end{array}$ & 1 & 0.1 & 19,3 & - & 11.1 & - & 8,2 & - & & & 0.101 & - & 0,046 & - & 18,8 & - \\
\hline Coprah & Tourteau & 1 & 0,4 & 40,4 & - & 7.8 & - & 32.7 & - & 0,087 & - & & & & & 47.8 & - \\
\hline & & 8 & 1.2 & 28,5 & 3,8 & 6.1 & 2,4 & 22,4 & 3,0 & & & 0.170 & 0,058 & 0,050 & 0,033 & 39.7 & 3,8 \\
\hline Coton & Graine & 1 & 1,2 & 32,4 & - & 20.7 & - & 11.7 & - & & & 0,020 & - & 0,084 & - & 7,3 & - \\
\hline & Tourteau & 4 & 0.7 & 17,3 & 3,8 & 6.7 & 3,9 & 10.6 & 3,5 & 0,054 & 0,017 & & & & & 27.5 & 3,9 \\
\hline & & 7 & 0.7 & 21,4 & 6,1 & 9,4 & 3,9 & 12,0 & 2,5 & & & 0,155 & 0,112 & 0,054 & 0,039 & 25,2 & 3,7 \\
\hline Datte & Noyau & 1 & 3.0 & 44,4 & - & 2.8 & - & 41,6 & - & & & 0,048 & - & 0,036 & - & 26,1 & - \\
\hline Epinard & Feuilles & 2 & 0.2 & 11.4 & 1,8 & 1,4 & 0,2 & 10,0 & 1,6 & & & 0.149 & 0,013 & 0.174 & 0,019 & 56,5 & 0,5 \\
\hline Fétuque & Foin & 1 & 1.5 & 34,4 & - & 12,7 & - & 21,7 & - & 0,054 & - & & & & & 29,9 & - \\
\hline Féverole & Graine & 1 & 1,0 & 11,9 & - & 0.1 & - & 11,8 & - & 0,037 & - & & & & & 37.7 & - \\
\hline $\begin{array}{l}\text { Haricot } \\
\text { Vert }\end{array}$ & Coproduits & 1 & 1.9 & 21,2 & - & 4,7 & - & 16.5 & - & 0,076 & - & & & & & 43,5 & - \\
\hline Lin & Tourteau & 2 & 1,0 & 14,7 & 0,1 & 8.7 & 1,6 & 6,0 & 1,8 & 0,083 & 0,052 & & & & & 21,4 & 0,3 \\
\hline Lupin & Graine & 2 & 0,6 & 14,2 & 2,1 & 2.6 & 0,1 & 11.6 & 2,0 & & & 0,095 & 0,026 & 0,084 & 0,013 & 39,9 & 4,3 \\
\hline Luzerne & Déshydratée & 2 & 2.3 & 31.7 & 3,0 & 12,2 & 2,7 & 19,5 & 0,2 & 0,056 & 0,024 & & & & & 29,3 & 9,1 \\
\hline & & 2 & 0,7 & 37.5 & 2,2 & 20,5 & 0,6 & 16.9 & 1,6 & & & 0,088 & 0,042 & 0.109 & 0,029 & 21,9 & 2,8 \\
\hline & Foin & 2 & 0,3 & 34.7 & 3,5 & 21,9 & 2,2 & 12.8 & 1,3 & 0,107 & 0,018 & & & & & 23,5 & 1,4 \\
\hline Luzerne + urée & Déshydratée & 2 & 1.1 & 28.1 & 2,1 & 13,9 & 1,4 & 14.2 & 0,7 & 0,135 & 0,047 & & & & & 34,5 & 4,6 \\
\hline Mais & DDG & 1 & 0,3 & 14,7 & - & 1,4 & - & 13,3 & - & 0,035 & - & & & & & 33,3 & - \\
\hline & Drêche & 1 & 0,8 & 14,8 & - & $-6,6$ & - & 21,4 & - & 0,012 & - & & & & & 24,1 & - \\
\hline & Ensilage & 2 & 1,5 & 21,7 & 0,4 & 9,2 & 0,0 & 12,5 & 0,4 & 0,081 & 0,035 & & & & & 32,2 & 5,8 \\
\hline & $\begin{array}{l}\text { Corn Gluten } \\
\text { Feed }\end{array}$ & 3 & 0,4 & 10,0 & 0,8 & 1,6 & 0,3 & 8,4 & 1,0 & 0,037 & 0,008 & & & & & 31,7 & 3,3 \\
\hline & Graine & 6 & 0,3 & 2,9 & 0,2 & 0,2 & 0,3 & 2,7 & 0,3 & 0,030 & 0,007 & & & & & 30.7 & 3,0 \\
\hline & & 1 & 0.1 & 3,2 & - & 0,3 & - & 2.9 & - & & & 0.111 & - & 0,005 & - & 15.8 & - \\
\hline & Solufactor & 1 & 0,2 & 10,3 & - & 1,3 & - & 9,0 & - & & & 0,075 & - & 0,051 & - & 34.7 & - \\
\hline & $\begin{array}{l}\text { Tourteau } \\
\text { de germe }\end{array}$ & 1 & 0,2 & 13,8 & - & 1,5 & - & 12,3 & - & 0,101 & - & & & & & 55.7 & - \\
\hline & & 1 & 0,4 & 12,0 & - & 2.7 & - & 9,3 & - & & & 0,070 & - & 0,223 & - & 39,2 & - \\
\hline Microorganismes & Levures & 2 & 0.2 & 4,7 & 0,9 & 0,5 & 0,1 & 4,2 & 0,9 & & & 0,046 & 0,016 & 0,060 & 0,001 & 28,5 & 6,0 \\
\hline Olive & Grignon & 1 & 1,5 & 49,5 & - & 35,6 & - & 13,9 & - & 0,210 & - & & & & & 21.8 & - \\
\hline & Drêche & 1 & 1,4 & 20,4 & - & 8,0 & - & 12,4 & - & 0,029 & - & & & & & 19,7 & - \\
\hline Orge & & 1 & 1,0 & 31,6 & - & 18,0 & - & 13,6 & - & & & 0,056 & - & 0,055 & - & 15,0 & - \\
\hline & Graine & 4 & 0,3 & 5.7 & 0,7 & $-0,2$ & 5,8 & 6,0 & 5,1 & 0,035 & 0,039 & & & & & 16,6 & 3,2 \\
\hline
\end{tabular}


Annexe 3. (suite)

\begin{tabular}{|c|c|c|c|c|c|c|c|c|c|c|c|c|c|c|c|c|c|}
\hline \multirow{2}{*}{ Famille } & \multirow{2}{*}{ Genre } & \multirow{2}{*}{$\begin{array}{l}\mathrm{Nb} \\
\text { èch }\end{array}$} & \multirow{2}{*}{$\begin{array}{c}\text { ETR } \\
(\% \text { MS) }\end{array}$} & \multicolumn{2}{|c|}{$\begin{array}{c}\text { ADF } \\
(\% \mathrm{MS})\end{array}$} & \multicolumn{2}{|c|}{$\begin{array}{l}\text { QADFnd } \\
\text { (\% MS) }\end{array}$} & \multicolumn{2}{|c|}{$\begin{array}{l}\text { QADFd } \\
\text { (\% MS) }\end{array}$} & \multicolumn{2}{|c|}{$\begin{array}{c}c_{\varnothing} A D F \\
\left(h^{-1}\right)\end{array}$} & \multicolumn{2}{|c|}{$\begin{array}{c}C_{M A D F} A \\
\left(h^{-1}\right)\end{array}$} & \multicolumn{2}{|c|}{$\begin{array}{c}d_{M A D F} \\
\left(\mathrm{~h}^{-1}\right)\end{array}$} & \multicolumn{2}{|c|}{$\begin{array}{l}\text { DTADF } \\
(\% \text { ADF })\end{array}$} \\
\hline & & & & Moy & $E T$ & Moy & $E T$ & Moy & $E T$ & Moy & $E T$ & Moy & $E T$ & Moy & $E T$ & Moy & $E T$ \\
\hline \multirow{2}{*}{ Palmiste } & Tourteau & 4 & 1.4 & 39,0 & 4,6 & 12,1 & 7,9 & 26.9 & 6,6 & & & 0.120 & 0,055 & 0.090 & 0,083 & 32,8 & 6,7 \\
\hline & $\begin{array}{l}\text { Tourteau } \\
\text { enrichi }\end{array}$ & 1 & 2,7 & 43,2 & - & 1.4 & - & 41,8 & - & 0,014 & - & & & & & 18,3 & - \\
\hline \multirow{6}{*}{ Petit pois } & Fane & 1 & 1,3 & 24.7 & - & 10,7 & - & 14.0 & - & 0,082 & - & & & & & 32,5 & - \\
\hline & $\begin{array}{l}\text { Gousses } \\
\text { pleines }\end{array}$ & 1 & 0.4 & 13,0 & - & 1,0 & - & 12,0 & - & 0,094 & - & & & & & 56.2 & - \\
\hline & $\begin{array}{l}\text { Plante } \\
\text { entière }\end{array}$ & 1 & 0,3 & 25,0 & - & 11,5 & - & 13,5 & - & & & 0.123 & - & 0.076 & - & 28,8 & - \\
\hline & \multirow{2}{*}{ Coproduits } & 2 & 0.7 & 19,3 & 4,1 & 1,7 & 2,2 & 17.6 & 6,3 & 0,085 & 0,021 & & & & & 51,9 & 2,4 \\
\hline & & 1 & 0.8 & 13,7 & - & 1.5 & - & 12,2 & - & & & 0,109 & - & 0,088 & - & 46.7 & - \\
\hline & $\begin{array}{l}\text { Tiges } \\
+ \text { feuilles }\end{array}$ & 1 & 0.2 & 18,3 & - & 6.7 & - & 11.6 & - & 0.120 & - & & & & & 42,3 & - \\
\hline Pois & Graine & 2 & 0,8 & 6.4 & 0,4 & $-1,1$ & 1,4 & 7,4 & 1,0 & 0,045 & 0,024 & & & & & 47,1 & 6,5 \\
\hline Pomme & Marc & 1 & 0.9 & 30.7 & - & 8,6 & - & 22.1 & - & 0,056 & - & & & & & 34,8 & - \\
\hline \multirow{5}{*}{$\begin{array}{l}\text { Pomme } \\
\text { de terre }\end{array}$} & Ensilage & 1 & 0.5 & 6.5 & - & 0.7 & - & 5,8 & - & 0,077 & - & & & & & 49,8 & - \\
\hline & Pelures & 1 & 0,6 & 8.1 & - & 1,8 & - & 6.3 & - & 0,097 & - & & & & & 48,2 & - \\
\hline & $\begin{array}{l}\text { Pelures } \\
\text { vapeur }\end{array}$ & 1 & 0.5 & 46,2 & - & 37.5 & - & 8.7 & - & 0,205 & - & & & & & 14,5 & - \\
\hline & Purée & 1 & 0,2 & 5,3 & - & 1.0 & - & 4,3 & - & & & 0.105 & - & 0.178 & - & 46,5 & - \\
\hline & Racine & 2 & 0.3 & 3.2 & 0,1 & 0.5 & 1,2 & 2,7 & 1,1 & 0,028 & 0,010 & & & & & 25.1 & 5,4 \\
\hline \multirow[t]{6}{*}{ Raisin } & Marc & 1 & 1,2 & 60.8 & - & 45,9 & - & 14,9 & - & 0,101 & - & & & & & 15,4 & - \\
\hline & \multirow[t]{2}{*}{ Pépin } & 3 & 0,2 & 65.1 & 2,0 & 56.4 & 2,1 & 8.7 & 0,2 & 0,101 & 0,026 & & & & & 8.3 & 1,2 \\
\hline & & 1 & 0,2 & 63,0 & - & 50,8 & - & 12,2 & - & & & 0.170 & - & 0.114 & - & 12,2 & - \\
\hline & \multirow[t]{2}{*}{ Pulpe } & 4 & 1.1 & 59,4 & 3,8 & 38,5 & 4,4 & 20,9 & 3,9 & 0,055 & 0,017 & & & & & 16,8 & 5,2 \\
\hline & & 3 & 0,5 & 57,8 & 2,7 & 40,8 & 5,7 & 17.1 & 3,7 & & & 0,073 & 0,013 & 0,059 & 0,014 & 12,0 & 3,5 \\
\hline & $\begin{array}{l}\text { Pulpe } \\
\text { enrichie }^{(3)}\end{array}$ & 1 & 1,4 & 53,0 & - & 31,1 & - & 21,9 & - & 0,145 & - & & & & & 29,2 & - \\
\hline Salsifis & Racine & 1 & 0,6 & 10.4 & - & 2,9 & - & 7.5 & - & 0,206 & - & & & & & 55,9 & - \\
\hline \multirow[t]{4}{*}{ Soja } & \multirow[t]{2}{*}{ Coque } & 1 & 3,2 & 42,8 & - & 6.9 & - & 35,9 & - & 0,052 & - & & & & & 38,9 & - \\
\hline & & 3 & 2,8 & 43,6 & 1,4 & 4.7 & 3,3 & 38.9 & 2,0 & & & 0,088 & 0,008 & 0,035 & 0,013 & 33,6 & 4,6 \\
\hline & Tourteau & 4 & 0.5 & 5,7 & 1,5 & 0,5 & 0,1 & 5,1 & 1,5 & & & 0,080 & 0,043 & 0,084 & 0,071 & 33,4 & 7,4 \\
\hline & $\begin{array}{l}\text { Tourteau } \\
\text { tanné }\end{array}$ & 2 & 0.4 & 5.9 & 1,6 & 0,3 & 0,3 & 5,6 & 1,3 & & & 0.068 & 0,040 & 0.034 & 0,005 & 29.6 & 7,2 \\
\hline Soja/colza & $\begin{array}{l}\text { Graine } \\
\text { Extrudée }\end{array}$ & 1 & 0.4 & 12,1 & - & 3.6 & - & 8,5 & - & & & 0,036 & - & 0,058 & - & 19,3 & - \\
\hline \multirow[t]{2}{*}{ Sorgho } & DDG & 1 & 1.7 & 40,9 & - & 14,8 & - & 26,1 & - & 0,011 & - & & & & & 9.9 & - \\
\hline & Graine & 1 & 1,0 & 3,3 & - & 0.7 & - & 2.6 & - & 0,084 & - & & & & & 45,9 & - \\
\hline \multirow[t]{2}{*}{ Tomate } & Pulpe & 3 & 0.7 & 43,8 & 1,3 & 24,5 & 1,6 & 19,3 & 0,8 & 0,146 & 0,037 & & & & & 30,9 & 1,1 \\
\hline & & 2 & 0,3 & 44,8 & 0,9 & 25,4 & 0,1 & 19,4 & 1,0 & & & 0,183 & 0,014 & 0,076 & 0,014 & 26.0 & 1,1 \\
\hline Topinambour & Racine & 1 & 1,3 & 6.0 & - & 1.5 & - & 4,5 & - & 0,102 & - & & & & & 47.5 & - \\
\hline Tournesol & Coque & 2 & 0,4 & 61,9 & 3,7 & 52,3 & 3,7 & 9,6 & 0,0 & 0,211 & 0,165 & & & & & 11,2 & 1,9 \\
\hline & $\begin{array}{l}\text { Coque } \\
+ \text { Amande }\end{array}$ & 1 & 0.5 & 35,0 & - & 26,5 & - & 8.5 & - & 0,175 & - & & & & & 18.0 & - \\
\hline & Tourteau & 1 & 0.7 & 28,0 & - & 19,8 & - & 8,2 & - & 0,075 & - & & & & & 16,2 & - \\
\hline
\end{tabular}

(1) Pulpe de betterave enrichie en mélasse + vinasses.

(2) Pulpe de raisin enrichie en jus de raisin

Moyennes (Moy) et écarts types (ET) calculés sur les échantillons les mieux ajustés individuellement par le modèle d'Ørskov et McDonald (1979) (Ø) ou le modèle de Mertens (1973) (M).

Pour des raisons de lisibilité, les tableaux ne présentent que les données relatives aux matières premières (en gris : modèle $\varnothing$, en blanc: modèle $\mathrm{M})$. 
Annexe 4. Paramètres de dégradation de l'ADL.

\begin{tabular}{|c|c|c|c|c|c|c|c|c|c|c|}
\hline \multirow{2}{*}{ Famille } & \multirow{2}{*}{ Genre } & \multirow{2}{*}{$\begin{array}{c}\mathrm{Nb} \\
\text { échant }\end{array}$} & \multicolumn{2}{|c|}{$\begin{array}{c}\text { ADL } \\
(\% \mathrm{MS})\end{array}$} & \multicolumn{2}{|c|}{$\begin{array}{c}\text { QADLnd } \\
\text { (\% MS) }\end{array}$} & \multicolumn{2}{|c|}{$c_{\varnothing} A D L\left(h^{-1}\right)$} & \multicolumn{2}{|c|}{$\begin{array}{l}\mathrm{DT} \mathrm{T}_{\varnothing \mathrm{ADL}} \\
\text { (\% ADL) }\end{array}$} \\
\hline & & & Moy & $E T$ & Moy & $E T$ & Moy & $E T$ & Moy & $E T$ \\
\hline Betterave & Pulpe & 12 & 1,8 & 0,6 & 0,9 & 0,3 & 0,066 & 0,033 & 23,4 & 10,5 \\
\hline Blé & $\begin{array}{l}\text { Drêche } \\
\text { +Soluble }\end{array}$ & 5 & 2,8 & 0,5 & 2,6 & 0,5 & 0,164 & 0,241 & 4,7 & 2,6 \\
\hline Coprah & Tourteau & 7 & 7,1 & 1,4 & 4,8 & 0,8 & 0,080 & 0,030 & 17,6 & 8,9 \\
\hline Coton & Tourteau & 2 & 5,8 & 3,7 & 3,8 & 1,8 & 0,114 & 0,081 & 20,2 & 13,6 \\
\hline Luzerne & Déshydratée & 4 & 8,4 & 1,9 & 5,6 & 1,3 & 0,077 & 0,026 & 17,9 & 2,7 \\
\hline $\begin{array}{l}\text { Luzerne } \\
\text { + Urée }\end{array}$ & Déshydratée & 2 & 6,3 & 0,6 & 4,2 & 0,3 & 0,272 & 0,073 & 27,1 & 0,1 \\
\hline Maïs & $\begin{array}{l}\text { Tourteau } \\
\text { de germe }\end{array}$ & 2 & 1,6 & 1,1 & 1,1 & 0,9 & 0,192 & 0,192 & 20,7 & 3,7 \\
\hline Olive & Grignon & 1 & 20,5 & - & 14,1 & - & 0,090 & - & 18,6 & - \\
\hline Palmiste & Tourteau & 4 & 11,2 & 4,4 & 8,2 & 3,6 & 0,056 & 0,022 & 11,3 & 3.7 \\
\hline Pomme & Marc & 1 & 11,8 & - & 6,3 & - & 0,086 & - & 27,3 & - \\
\hline \multirow{4}{*}{ Raisin } & Marc & 1 & 42,2 & - & 35,6 & - & 0,075 & - & 8,7 & - \\
\hline & Pépin & 4 & 50,7 & 2,8 & 49,2 & 1,4 & 0,126 & 0,055 & 1,6 & 1,3 \\
\hline & Pulpe & 7 & 38,3 & 3,8 & 28,6 & 4,5 & 0,069 & 0,032 & 13,3 & 5,8 \\
\hline & $\begin{array}{l}\text { Pulpe } \\
\text { enrichie (1) }\end{array}$ & 1 & 35,0 & - & 21,0 & - & 0,242 & - & 32,1 & - \\
\hline Tomate & Pulpe & 5 & 24,3 & 2,0 & 22,5 & 1,8 & 0,146 & 0,202 & 4,8 & 5,2 \\
\hline \multirow{2}{*}{ Tournesol } & Coque & 2 & 22,2 & 1,8 & 19,5 & 0,4 & 0,466 & 0,579 & 9,3 & 7,4 \\
\hline & $\begin{array}{l}\text { Coque } \\
+ \text { Amande }\end{array}$ & 1 & 12,9 & - & 11,0 & - & 0,218 & - & 11,5 & - \\
\hline
\end{tabular}

(1) Pulpe de betterave enrichie en mélasse + vinasses.

Aliments ayant présenté une évolution significative dans le temps de la dégradation de l'ADL

Paramètres moyens (Moy) + écarts types (ET) calculés sur les échantillons ajustés individuellement par le modèle d'Ørskov et McDonald (1979). 
